\title{
Identifying possible underlying mechanisms of developmental speech sound disorders with the Nonword Repetition Task
}

\author{
Cummings, Alycia ${ }^{1}$ and Anna Ehrhorn ${ }^{2}$
}

${ }^{1}$ Idaho State University

${ }^{2}$ University of South Carolina

Contact Author: Alycia Cummings Communication Sciences \& Disorders - Meridian Idaho State University 1311 E. Central Drive Meridian, ID 83642

Phone: 858.245.7222

Keywords: children, speech sound disorders, phonological disorders, phonology, nonword repetition, phonological encoding, articulation 


\section{Acknowledgements.}

This research was supported by NIH grant numbers R15DC013359 (from the National Institute On Deafness and Other Communication Disorders) and C06RR022088 (from the National Center for Research Resources) awarded to the first author. The content is solely the responsibility of the authors and does not necessarily represent the official views of the National Institutes of Health. The authors would like to thank the children and their families for participating in this research project. We would also like to thank Ashley Rach, Mary Fabian, and Kristen Hughes for their help with the transcription and organization of the nonword repetition data.

\section{Author Disclosure Statement.}

The authors do not have any financial or non-financial relationships relevant to the content of this manuscript. The authors alone are responsible for the content and writing of this manuscript. 


\begin{abstract}
Purpose: The Nonword Repetition Task (NRT) was used as a tool to examine possible underlying mechanisms of developmental speech sound disorders (SSD). Specifically, deficits related to phonological encoding were examined.

Method: Twenty-four children with SSD (3-7 years) and 24 typically developing (TD) children were administered the NRT. Four accuracy measures were calculated: percent consonants correct (PCC), consonant place of articulation, consonant manner of articulation, and consonant voicing. In addition, the verbal response time to produce each nonword was measured.

Results: Children with SSD were less accurate in their repetition of nonwords than TD children, even after their speech sound production ability was taken into account, suggesting that a deficit beyond articulation was affecting their performance. Children with SSD demonstrated phonological encoding difficulties, as their ability to accurately represent the phonetic articulation characteristics of consonants was impaired. Moreover, children with SSD demonstrated much faster verbal response times than their TD peers; more accurate NRT responses were correlated with slower verbal response times.
\end{abstract}

Conclusion: These results suggest that children with SSD may have phonological encoding deficits, which might negatively impact their ability to accurately produce speech sounds. The NRT could be used to help identify underlying mechanisms of SSD, such a deficit in phonological encoding, which could lead to more effective treatment approaches. 


\section{Introduction}

Children with functional speech sound disorders (SSD) have difficulty producing and correctly using some sounds of their target language (Gierut, 1998). That is, they are unable to use speech sounds that are age and dialect appropriate. A SSD can affect a speaker's production and/or mental representation of speech sounds. Specifically, a SSD may be phonetic in nature, meaning that the difficulty lies in how sounds are produced, thereby involving a motoric component; and/or the difficulty may be phonemic in nature, implying that the disorder may have a cognitive or linguistic basis, thereby affecting how speech sound information is encoded, stored, represented, and retrieved in the mental lexicon (Gierut, 1998). While treatment has successfully been provided to children with SSD for decades (van Riper \& Irwin, 1958), it is still unknown what underlying mechanisms might account for this disorder.

Nonword repetition. Nonword repetition is a potentially ideal task to use to examine some of the underlying mechanisms of speech sound perception and production. While initially designed as a measure of verbal working memory (Gathercole \& Baddeley, 1990), it is now commonly understood that nonword repetition tasks involve many different levels of information processing (Aslin \& Smith, 1988; Bowey, 1996, 2006; Gathercole \& Baddeley, 1997; Gathercole, 2006). Accurate performance on nonword repetition tasks starts with the perception and discrimination of the acoustic signal. The acoustic-phonetic signal is then mapped onto the phonological representations of the appropriate phonemes, while maintaining the order of the phonologically coded string in working memory. Finally, the articulatory movements necessary to repeat the nonword are planned and executed, resulting in the articulation of the word (Dollaghan \& Campbell, 1998; Munson, Edwards, \& Beckman, 2005; Munson, Kurtz, \& Windsor, 2005). 
Even though nonword repetition tasks do target a wide range of cognitive processes, the vast majority of the research surrounding nonwords has focused on the higher-order working memory and language features of the task to identify language impairments in various populations, rather than the speech perception and production aspects (D. V. M. Bishop, Adams, \& Norbury, 2006; Botting \& Conti-Ramsden, 2001; Conti-Ramsden, Botting, \& Faragher, 2001; Dollaghan \& Campbell, 1998; Ellis Weismer et al., 2000; Gathercole \& Baddeley, 1990; Gathercole, Willis, Baddeley, \& Emslie, 1994; Gathercole, 2006; Graf Estes, Evans, \& Else-Quest, 2007; Grant et al., 1997; Gray, 2003; Kamhi \& Catts, 1986; Laws \& Gunn, 2004; Marton \& Schwartz, 2003; Montgomery, 2004). However, nonword repetition tasks also have the potential to be useful in the assessment of children with SSD because they require a broad range of speech skills, such as speech perception (Coady \& Evans, 2008) and phonological encoding ${ }^{1}$ (Bowey, 2006), as well as nonlinguistic oral-motor planning and control/articulation (Krishnan et al., 2013). To clarify, nonword repetition tasks can potentially provide information regarding additional deficits children with SSD might have, above and beyond the misarticulation of speech sounds. Moreover, given their inexpensive nature and ease of administration and scoring, nonword repetition tasks could be used by effectively by clinicians during their assessment of children with SSD in order to provide information regarding children's overall speech perception and production abilities.

Nonword repetition in children with SSD. Only a few nonword repetition studies have involved children with phonological disorders or SSD (Munson, Edwards, et al., 2005; Yoss \& Darley, 1974). One early study by Yoss and Darley (1974) attempted to identify behaviors that would differentiate children with "moderate to severe defective articulation" from typically

\footnotetext{
${ }^{1}$ Phonological encoding can be defined as "the construction of a phonetic plan for the utterance" (Hartsuiker, Bastiaanse, Postma, \& Wijnen, 2005, p. 5).
} 
developing (TD) children. Thirteen nonwords were presented in consonant-vowel-consonant (CVC) form and contained twelve different consonants, $/ \mathrm{f} \int \mathrm{b} \theta \int \mathrm{f} \mathrm{k} \mathrm{g} 1 \mathrm{~s} \mathrm{z} \mathrm{r} /$, and four vowels, $/ \mathrm{a} u \Lambda æ /$, that ranged from high to low frequency of occurrence in children's speech as well as for their frequent misarticulation by young children. Unfortunately, the nonword repetition task outcomes were combined with other speech production tasks so that only a total number of articulation errors were reported. The children with defective articulation produced over 1100 errors on the speech tasks while the typically developing children produced 172 errors. Thus, as expected, the group differences in speech production were extreme and children with moderate to severe speech production impairments were easily differentiated from children with typical articulation skills.

A more recent study by Munson, Edwards, and Beckman (2005) compared the nonword repetition skills of children with phonological disorders with TD children. Munson et al. (2005) used their own nonword repetition task (Edwards, Beckman, \& Munson, 2004) that varied the diphone frequency of the nonwords. Both groups of children had more difficulty producing the low-frequency sound sequences than the high-frequency sound combinations. While the children with phonological disorders were less accurate than their TD peers, they did not have greater difficulty with the low-frequency diphones than their age-matched peers.

In addition, in order to examine whether children's ability to accurately produce nonwords was related to either their speech perception and/or their ability to produce sounds in real words, Munson et al. (2005) had both groups of children complete a gated-word recognition task and a picture naming/speech task. Interestingly, while the ability of the children with phonological disorders to accurately produce nonwords was related to their experience in perceiving and producing sounds in real words, this was not the case for TD children. Thus, Munson, Edwards, 
and Beckman (2005) suggested that children with phonological disorders had deficits in the ability to accurately create both acoustic-auditory perceptual representations and articulatory motor representations necessary for speech production. In other words, by using a nonword repetition task (amongst others), Munson and colleagues were able to provide additional evidence for poor perceptual abilities in children with phonological disorders (leading to phonological encoding and representation deficits), as well as evidence of poor speech production.

The present study. The work by Munson, Edwards, and Beckman (2005) suggests that children with speech impairments can have deficits both in speech production, as well as in speech perception and phonological encoding/representation. The present study sought to replicate and extend these nonword perception and production findings in children with SSD and typically developing (TD) children by using a nonword repetition task that is commonly used in the United States (Archibald \& Gathercole, 2006; Coady \& Evans, 2008; Ellis Weismer et al., 2000; Shriberg et al., 2009; Thal, Miller, Carlson, \& Vega, 2005): the Nonword Repetition Task (NRT) (Dollaghan \& Campbell, 1998). Specifically, aspects of phonological encoding and speech production in the NRT were targeted in the present study.

The phonological encoding of children's NRT responses was measured with detailed phonetic articulation accuracy measures addressing the binary/distinctive features of consonant place, manner, and voicing (Chomsky \& Halle, 1968; Clements \& Hume, 1995; Halle, Vaux, \& Wolfe, 2000; Jakobson, Fant, \& Halle, 1952; McCarthy, 1988). It was predicted that more accurate phonological encoding would result in more accurate phonetic articulation accuracy meaning that if the individual consonants on the NRT were encoded correctly, they would be produced with the correct articulatory placement, manner, and voicing. It was expected that 
children with speech production problems would be less accurate than children without speech impairments; however, it was of interest whether their phonetic encoding/articulation patterns were similar to TD peers. If the overall patterns of phonetic accuracy were similar for children with and without SSD, then it might be that the differences in nonword repetition performance could be attributed primarily to speech production problems. However, if different phonetic accuracy patterns were found, it would be possible that phonological encoding deficits were affecting the NRT performance of children with SSD.

Phonological encoding abilities were also assessed using a dynamic measurement: verbal response time (RT) to produce a nonword. To clarify, examining the time it takes to initiate the production of a nonword can provide additional information regarding the language and speech motor planning processes involved in producing a word (Sasisekaran \& Byrd, 2013). In other words, if poor nonword repetition accuracy was due to deficits in some of the linguistic-speech processing stages (such as phonological encoding), then differences could also be observed in verbal RTs. If children with and without SSD have similar verbal RTs, then it would also suggest that that their ability to fully perceive, encode, process, and produce nonwords is similar in nature. Alternatively, differences in RTs would suggest that children with SSD have a different and perhaps less accurate and/or efficient approach to nonword repetition tasks than their TD peers. Such a finding could indicate linguistic (phonemic) and/or motor planning difficulties, such as deficits in phonological encoding.

Finally, it was questioned whether children's ability to produce nonwords correctly (or incorrectly) could be related to the fact that the speech sounds were presented in unfamiliar nonwords, as compared to real words. Thus, the relationship between children's ability to produce the same consonant sounds in the NRT and in familiar, real words on a standardized 
assessment of children's articulation, the Goldman-Fristoe Test of Articulation - 2 (GFTA-2)

(Goldman \& Fristoe, 2000), was examined. If the two groups of children demonstrated similar levels of NRT accuracy once their ability to produce the same NRT consonants in familiar real words was controlled, then it could be assumed that group differences on the NRT were solely due to speech production impairments. However, if group differences were still present, even after controlling for general speech production ability, then such a result would suggest that children with SSD have additional deficits, such as in phonological encoding.

In sum, the present study used familiar and/or standardized measures of real and nonword production in an attempt to identify some of the possible underlying mechanisms of SSD. The specific goals of the study were to: 1) compare the NRT production accuracy of children with SSD to that of their age-matched peers on a common nonword repetition task - the NRT (Dollaghan \& Campbell, 1998), 2) measure the NRT verbal response times to look for differences in a cumulative measure of language and motor planning processes in the children with and without speech impairments, and 3) examine whether the sounds produced correctly and incorrectly in real words on a standardized speech assessment were related to/and or predicted sound accuracy on the NRT.

\section{Methods}

Participants. Forty-eight children (15 females, aged 3.08 to 6.92 years) participated in the study: 24 children ( 7 female, mean age $=4.80$ years $)$ with functional speech sound disorders (SSD) and 24 typically developing (TD) children ( 8 female, mean age $=5.09$ years). All children met the following entry criteria (Table 1):

$<$ Insert Table 1 about here $>$

- Residency in a monolingual English-speaking household; 
- Hearing within normal limits as determined by a standard audiometric screening (American National Standards Institute, 1991);

- An oral-peripheral mechanism exam completed within normal limits as determined by the protocol developed by Robbins and Klee (1987);

- Receptive picture vocabulary skills within normal limits (standard scores between 85 and 115) as assessed by the Peabody Picture Vocabulary Test-IV (PPVT-IV; Dunn \& Dunn, 2007);

While the TD children were required to have a minimum standard score of 90 on a standardized test of speech articulation, the Goldman-Fristoe Test of Articulation-2 (GFTA-2; Goldman \& Fristoe, 2000), the children with SSD met the following additional criteria:

- A previous diagnosis of SSD from a licensed and clinically certified speech-language pathologist (CCC-SLP)

- A maximum standard score of 84 on the GFTA-2 (Goldman \& Fristoe, 2000);

- A reduced consonant inventory, excluding a minimum of three target English sounds from their respective phonemic inventories (e.g., Dinnsen, Chin, Elbert, \& Powell, 1990). Sounds excluded from the inventory were identified based on extensive phonological probe measures using the Assessment of English Phonology (AEP; (Barlow, 2003). Specifically, phonemic status of a sound was established following the criterion of two unique sets of minimal pairs (e.g. 'sing'-'ring' or 'run'-'rub'), regardless of whether they were correct relative to adult production (Gierut, Simmerman, \& Neumann, 1994).

In addition to the above assessments, all 24 of the children with SSD received additional standardized testing of their language and nonverbal cognition abilities. To be included in the sample, these children had to meet the following criteria: 
- Nonverbal cognitive skills within normal limits as assessed by the Brief IQ Screener on the Leiter International Performance Scale - Revised (Leiter-R; Roid \& Miller, 1997);

- Receptive and expressive language abilities within normal limits as assessed by the Test of Early Language Development - 3 (TELD-3; Hresko, Reid, \& Hammill, 1999) Spoken Language Quotient (SLQ).

Thus, all of the children with SSD had a diagnosis of SSD, with no concomitant disorder diagnoses, such as language impairment, autism spectrum disorders (ASD), attention-deficit hyperactivity disorder (ADHD), and/or emotional disturbance.

Speech Production Measures. Three separate assessments of speech sound production were used in the study: 1) a standardized test of articulation: the GFTA-2; 2) the Dollaghan \& Campbell (1998) Nonword Repetition Test (NRT)2; and 3) a potential predictor of NRT performance which was based on each child's production of sounds on the GFTA-2: the GFTA2/NRT Predictor.

GFTA-2 Stimuli. The Sounds in Words subsection of the GFTA-2 is composed of 34 colored line drawings in an easel booklet targeting 53 words. Within those words, 77 singleton consonant sounds and two-element consonant blends (e.g., "st", "tr") are specifically targeted in their viable word positions (initial, medial, final).

GFTA-2 Procedure. Following the procedures outlined in the test manual, each child was shown each of the pictures and the experimenter would point to the picture or parts of the picture and ask, "What's this?" If the child did not spontaneously produce the words, the experimenter would first give the child a semantic cue, such as "You cut food with this (knife)" or "You wear this clothing to bed (pajamas)". If the child still did not respond, the experimenter would use a

\footnotetext{
${ }^{2}$ Henceforth referred to as the NRT.
} 
delayed imitation procedure so that some words and time separated the targeted word as spoken by the experimenter and the child's production, such as "This is a knife. What is it?"

After the GFTA-2 was administered and narrowly transcribed, a Percentage of Consonants Correct (PCC) measure (Shriberg, Austin, Lewis, McSweeny, \& Wilson, 1997; Shriberg \& Kwiatkowski, 1982; Shriberg, 1993) was calculated by identifying the number of consonants the child produced correctly out of 152 (the total number of consonants contained in all of the target words on the entire GFTA-2). In other words, to calculate the PCC, the underlying representation (UR; i.e., the adult target production of each word) was mapped to each child's surface production (SR; i.e., what was actually produced for each word) and the correct/incorrect sound productions were identified. Each phoneme was scored as correct or incorrect in relation to its target phoneme. Phoneme additions, omissions, substitutions, and distortions were scored as incorrect.

NRT Stimuli. The NRT is composed of 16 nonwords with four stimuli each containing one, two, three, and four syllables (Dollaghan \& Campbell, 1998; Table 2). The nonwords were made from 11 consonant phonemes and 9 vowel phonemes presented in an alternating consonantvowel (CV) pattern, and did not include the later developing sounds (e.g., /r/ and /s/). No weak syllables were produced because only tense/stressed vowels (e.g., /i/ and /u/) were used, helping to differentiate the nonwords from real English words, which typically follow a strong-weak stress pattern (e.g., "baby"). The nonwords were pre-recorded with a computer-generated voice and were presented via a computer-based program, Adobe Audition ${ }^{\circledR}$.

NRT Procedure. The NRT was explained to the children during both the pre-treatment assessment and post-treatment assessment sessions by stating, "Now, you will hear someone (an "alien") from the computer say a funny word. I want you to repeat the word to me, so I can 
understand it." Thus, the NRT was a phonetic imitation task (Wells, 1995). After each one of the nonwords was produced by the computer voice, there was a 2 -second break to allow the child to repeat the nonword to their best ability.

After the NRT was administered and narrowly transcribed, two measures were calculated. First, a PCC measure (e.g., (Shriberg et al., 1997; Shriberg \& Kwiatkowski, 1982; Shriberg, 1993) was calculated by identifying the number of consonants the child produced correctly out of 56 (the total number of consonants contained in the 16 nonwords on the NRT). Similar to what was reported by Dollaghan and Campbell (1998), when children added and/or omitted syllables during their nonword production, the PCC scoring occurred after aligning the child's production as closely as possible to the target nonword, using vowels as syllable anchors to maximize the child's score.

In addition to the PCC measure, the phonetic accuracy of each NRT consonant was evaluated in terms of its place, manner, and voicing articulation characteristics. Following a similar procedure outlined in Munson, Edwards, and Beckman (2005), the place (e.g., labial, labiodental, alveolar, post-alveolar, velar), manner (e.g., stop, fricative, affricate), and voicing (e.g., voiceless or voiced) characteristics of the produced consonant were compared separately with the target consonant, with each characteristic being worth either one point (i.e., accurate) or zero points (i.e., incorrect). The number of points for each of the three characteristics were individually summed and divided by the target point value of 56 , resulting in accuracy measures for Place of Articulation, Manner of Articulation, and Voicing.

Children's verbal response times (RTs) for the NRT were measured off-line using Adobe Audition ${ }^{\circledR}$. Specifically, RTs were calculated by measuring (in milliseconds) the duration of time between the onset of the computer's production of each nonword and the onset of each 
child's production of the nonword. In other words, a child's RT was calculated from the earliest point at which he/she was presented with auditory information for each nonword. Since the words were pre-recorded, the duration of each nonword was consistent across all children. Thus, each child was presented with the same amount of auditory information prior to producing the nonwords. Since there were four different syllable lengths for the nonwords, with four nonwords in each group, both mean and median values for each NRT syllable length were calculated for each child. Each child's four median RTs (one for each syllable length) were included in the RT analyses (note: mean RT values yielded similar results).

GFTA-2/NRT PCC Predictor Procedure. This assessment was completed off-line, using the information gathered from the administration of the GFTA-2. Each consonant and vowel on the Predicted NRT was linked to a specific consonant or vowel that was present in the same word position (initial, medial, or final) on the GFTA-2; this allowed for consistency in scoring across participants ${ }^{3}$. Once each GFTA-2 target consonant or vowel was identified, the experimenter examined what the child produced for that sound on the GFTA-2 (i.e., was it correct or not) and then transferred that information to the coding form. For example, if the child produced the word-initial phoneme, /n/, correctly on the GFTA-2 (in the word "knife"), the child was predicted to produce all word-initial/n/ phonemes correctly on the NRT (i.e., on /narb/, /noItauf/, /naitfouverb/, and /nartortauvub/). This information was used to create "predicted" NRT productions of each child and provided data for the GFTA-2/NRT PCC Predictor measurements, similar to what was described above for the actual NRT. Thus, the GFTA-2/NRT PCC Predictor was designed to be an optimal estimation of children's NRT consonant production performance.

\footnotetext{
3 One vowel on the NRT ("oy": /or/) was not targeted on the GFTA-2 ; thus, words containing that sound had one fewer phoneme/vowel to contribute to the calculations.
} 
Reliability transcription and scoring. The GFTA-2 and NRT administrations were digitally audio-recorded and highly trained transcribers narrowly transcribed both samples. All of the samples were reliability-checked by a second transcriber; both transcribers agreed at least $85 \%$ of the time on the speech sample transcription. This was calculated by dividing the number of phoneme agreements by the total number of phoneme agreements and disagreements. If this threshold was not reached, the speech sample in question was re-transcribed until two transcribers reached the designated threshold. Overall, transcriber reliability ranged from 90$98 \%$.

Experiment Design. This study sought to answer three separate, but related questions. Each question required different types of analyses. To be the most concise and straightforward, each analysis will be discussed below, directly prior to its respective result. When necessary, Greenhouse-Geisser corrected p-values are reported. Bonferroni corrected p-values for multiple analyses were also used to identify significant effects.

\section{Results}

Question \#1: Do children with SSD perform similarly to their TD peers on a test of nonword repetition? A one-way ANOVA was completed for the NRT PCC to examine the effect of Group (TD, SSD). In addition, the phonetic articulation accuracy of the children's productions was evaluated in terms of the place, manner, and voicing characteristics of each target consonant. A repeated measure ANOVA was completed to examine the effect of Group (TD, SSD) on consonant phonetic articulation accuracy (Place, Manner, Voicing).

NRT PCC. The main effect of group was strongly significant $(\mathrm{F}(1,46)=40.476, \mathrm{p}<.0001$, $\eta_{\mathrm{p}}^{2}=.468$; Figure 1$)$, with TD children having significantly higher PCC scores $(\mathrm{m}=79.83 \%$, SD 
$=14.44)$ than children with $\operatorname{SSD}(\mathrm{m}=50.11 \%, \mathrm{SD}=17.77)$. Thus not surprisingly, TD children were much more accurate in producing unfamiliar nonwords than were children with SSD.

NRT Phonetic Articulation Accuracy. Overall, children with SSD demonstrated significantly less phonetic articulation accuracy than did their TD peers $\left(F(1,46)=32.371, \mathrm{p}<.0001, \eta_{\mathrm{p}}^{2}=\right.$ .413) (Figure 1, Table 2). A significant difference in the phonetic accuracy measures was also observed $\left(\mathrm{F}(2,92)=80.059, \mathrm{p}<.0001, \eta_{\mathrm{p}}{ }^{2}=.635\right)$. Post-hoc pairwise comparisons revealed that overall children's correct production of the place of articulation of a target consonant was the least accurate, with the manner of articulation being significantly more accurate than the place of articulation measure $(\mathrm{p}<.0001)$. Children were the most accurate in producing the correct voicing of a target consonant $(\mathrm{p}<.0001)$.

A Group $x$ Phonetic Articulation Measure interaction was also observed $(F(2,92)=15.971, p$ $<.0001, \eta_{\mathrm{p}}{ }^{2}=.258$; Figure 1). Post-hoc one-way ANOVAs revealed that as compared to the children with SSD, the TD children were significantly more accurate in producing the correct place of articulation $\left(\mathrm{F}(1,46)=39.330, \mathrm{p}<.0001, \eta_{\mathrm{p}}{ }^{2}=.461\right)$, manner of articulation $(\mathrm{F}(1,46)=$ $\left.30.161, \mathrm{p}<.0001, \eta_{\mathrm{p}}{ }^{2}=.396\right)$, and voicing characteristics of the target consonant $(\mathrm{F}(1,46)=$ $\left.16.943, \mathrm{p}<.0001, \eta_{\mathrm{p}}{ }^{2}=.269\right)$.

In addition, when just the TD children's data were examined, there was no difference in the place of articulation and manner of articulation accuracy measures, but the voicing accuracy was significantly higher than the other two measures $(\mathrm{p}<.004)$. Alternatively, children with SSD were the least accurate in their consonant place of articulation accuracy, which was significantly less accurate than the manner of articulation $(\mathrm{p}<.0001)$, which was subsequently less accurate than the voicing $(\mathrm{p}<.0001)$ of the target consonant (Table 2$)$.

$<$ Insert Figure 1 about here $>$ 
$<$ Insert Table 2 about here $>$

Question \#2: Do children with SSD have NRT verbal response times (RTS) that are similar to their TD peers? A repeated measure ANOVA was completed to examine whether NRT median RTs differed across syllable length (One, Two, Three, Four) for either Group (TD, SSD). In addition, to examine the possible relationship between the overall median RT measures and NRT accuracy measures, four correlations (PCC, Place of Articulation, Manner of Articulation, and Voicing) were completed for the entire group of children. Finally, to examine the broader implications of the NRT verbal RTs, two additional correlations were completed with the standardized test standard scores of the GFTA-2 (articulation) and PPVT-4 (receptive vocabulary).

NRT Median RT. The main effect of group was significant $\left(\mathrm{F}(1,46)=12.435, \mathrm{p}<.002, \eta_{\mathrm{p}}{ }^{2}=\right.$ .213). The children with SSD demonstrated significantly faster NRT median RTs than did the TD children (Table 3$)$. A significant effect of syllable length was also observed $(F(3,138)=$ 252.139, $\left.\mathrm{p}<.0001, \eta_{\mathrm{p}}^{2}=.846\right)$. Post-hoc pairwise comparisons revealed that children's median RTs to the one syllable nonwords were significantly faster than those to the two (syllable nonwords ( $\mathrm{p}<.007)$, which were significantly faster than the three syllable nonword RTs $(\mathrm{p}<$ $.0001)$, which were subsequently significantly faster than four syllable nonword RTs $(\mathrm{p}<.0001)$.

In addition, a Group x Syllable Length interaction was observed $(F(3,138)=3.322, p<.04$, $\eta_{\mathrm{p}}^{2}=.067$; Figure 2). Post-hoc one-way ANOVAs revealed that while the two groups of children did not significantly differ in their median RTs to the one syllable words, the children with SSD had significantly faster median RTs for the two $\left(\mathrm{F}(1,46)=8.926, \mathrm{p}<.005, \eta_{\mathrm{p}}{ }^{2}=.163\right)$, three $\left(\mathrm{F}(1,46)=16.625, \mathrm{p}<.0001, \eta_{\mathrm{p}}^{2}=.265\right)$, and four $\left(\mathrm{F}(1,46)=9.135, \mathrm{p}<.005, \eta_{\mathrm{p}}^{2}=.166\right)$ syllable nonwords, as compared to the TD children. 
Upon examining the individual group RT data separately, both groups of children demonstrated a similar pattern of responses: no difference in the median RTs for one and two syllable nonwords, with the three syllable nonwords being produced significantly slower $(\mathrm{p}<$ .0001 for both groups), and the median RT values for the four syllable nonwords being the slowest ( $\mathrm{p}<.0001$ for both groups) (Table 3, Figure 2).

$<$ Insert Table 3 about here $>$ $<$ Insert Figure 2 about here $>$

NRT x Accuracy Correlations. Children's overall median NRT verbal RT measures were positively correlated with the NRT PCC measure $(\mathrm{r}=.352, \mathrm{p}<.02)$, as well as the place of articulation $(\mathrm{r}=.370, \mathrm{p}<.02)$ and manner of articulation $(\mathrm{r}=.405, \mathrm{p}<.005)$ of the target consonants (Figure 3). In other words, children's NRT production accuracy increased with longer/slower RTs. The median RT values did not correlate with the consonant voicing accuracy measures.

\section{$<$ Insert Figure 3 about here $>$}

NRT x Standardized Test Correlations. Children's overall median NRT RT was also positively correlated with standardized test measures. Standard scores on the GFTA-2 $(r=.405$, $\mathrm{p}<.005$ ) were positively correlated with larger/slower NRT RTs (Figure 4). Thus, children with more accurate speech articulation abilities, as measured by the GFTA-2, had slower NRT verbal RTs. In addition, the overall median RT measures were positively correlated with the standardized assessment of receptive vocabulary, PPVT-4 $(\mathrm{r}=.492, \mathrm{p}<.0001)$, meaning that children with higher vocabulary standard scores had larger/slower verbal RTs (Figure 4).

$<$ Insert Figure 4 about here $>$ 
Question \#3: Does a child's ability to produce speech sounds in familiar words predict his/her ability to produce unfamiliar nonwords? A Pearson correlation coefficient was calculated to determine the relationship between the NRT PCC and the GFTA-2/NRT PCC Predictor. A strong positive correlation was found $(\mathrm{r}(48)=.784, \mathrm{p}<.0001)$, indicating that children who were predicted to produce more consonants correctly on the NRT actually did so. Thus, given the relationship between speech production and NRT performance, a one-way between-subjects ANCOVA (co-varying out GFTA-2/NRT PCC Predictor scores at $80.65 \%$ correct) was completed for the NRT PCC to examine the effect of Group (TD, SSD).

ANCOVA results. GFTA-2/NRT PCC Predictor scores were significantly related to NRT PCC scores $\left(\mathrm{F}(1,45)=24.461, \mathrm{p}<.0001, \eta_{\mathrm{p}}^{2}=.352\right)$. The main effect of group was also significant, though to a much smaller extent than when speech production ability was not addressed $\left(F(1,45)=5.322, p<.03, \eta_{p}^{2}=.106\right)$, with TD children having significantly higher PCC scores $(m=70.94 \%, \operatorname{SEM}=3.23)$ than children with $\operatorname{SSD}(m=58.95 \%, \mathrm{SEM}=3.23)$. In other words, though a group difference in NRT PCC was observed, it was much smaller when children's speech production abilities were also taken into account. Thus, regardless of speech production accuracy, children with SSD still perform more poorly on the NRT than do their same age TD peers.

\section{Discussion}

This study used a measure of nonword repetition: the Dollaghan \& Campbell (1998) Nonword Repetition Task (NRT) in order to examine possible underlying mechanisms of speech sound disorders (SSD). The NRT was used to identify possible deficits children with SSD might have in comparison to typically developing (TD) children, specifically in relation to the phonological encoding and speech production of nonwords. Goals were to first identify potential 
overall group differences in nonword repetition performance, and then to examine how the phonetic articulation encoding patterns of the groups differed. Children's verbal response times (RT) were used as a dynamic measure of the timing of the linguistic and motor planning processes leading up to the production of a nonword. Finally, the speech production relationship between real words and nonwords was examined.

Do children with SSD perform comparably to their TD peers on the NRT? Unremarkably, children with typical speech production skills performed more accurately on the NRT than did children with SSD. Thus, TD children were more proficient in producing never-before heard nonwords than children with SSD. These results support the previous findings of Munson and colleagues (2005) that demonstrated that children with SSD were less accurate than their agematched peers in repeating nonwords correctly. These results also extend the findings of Munson et al. (2005) by using a common nonword repetition task - the NRT; thus, it is easier to compare the outcomes of TD children and children with SSD in the present study with prior studies' results using children of a variety of ages and language ability (Archibald \& Gathercole, 2006; Coady \& Evans, 2008; Ellis Weismer et al., 2000; Shriberg et al., 2009; Thal et al., 2005).

While the group differences were unremarkable, the large disparity between groups was somewhat surprising. The NRT (Dollaghan \& Campbell, 1998) was designed to target 11 earlyacquired (Bleile, 2006; Goldman \& Fristoe, 2000; Shriberg, 1993) consonant sounds: /n b p d t v $\mathrm{fg} \mathrm{k} \mathrm{\&} \mathrm{f} /$ to theoretically make it easier for children to produce the words. Unfortunately, all but three of the children with SSD had difficulty correctly producing at least two of the NRT sounds (Table 1, Appendices A \& B). For example, many children could not accurately produce their affricates, "ch", /tf/, and "j", / $/ \mathrm{b} /$, which occurred in ten of the nonwords; thus, incorrect 
affricate production resulted in a much lower NRT score. It would appear that though the NRT (Dollaghan \& Campbell, 1998) was designed target earlier acquired sounds, the children with SSD in the present study still had difficulty producing some of the target sounds.

In addition, the phonetic articulation accuracy of the children's productions differed. More specifically using a similar procedure as that described by Munson, Edwards, and Beckman (2005), the place of articulation, manner of articulation, and voicing characteristics of the children's produced consonants were compared to the target consonants on the NRT. Again unsurprisingly, the TD children were more accurate overall in their phonetic articulation accuracy, and the voicing characteristics were the easiest (i.e., most accurate) for both groups. What was interesting was that while TD children had similar levels of accuracy for both place and manner of articulation of the target phonemes, the children with SSD were better able to preserve the manner of articulation, as compared to the place of articulation of the target consonants.

These results suggest that phonological encoding deficits are present in children with SSD. Specifically, there appears to be a continuum in terms of accurate encoding (and production) of the phonetic information, with consonant voicing being the easiest to encode and produce correctly, followed by the consonant's manner of articulation, with the consonant's place of articulation being the most difficult to preserve correctly in encoding and production. One explanation for these findings is that children with SSD have difficulty accurately perceiving and encoding the consonants in terms of a consonant's acoustic prominence and accessibility. These results suggest that consonant voicing might be the most prominent acoustic cue while the place of articulation might be represented by a much more subtle acoustic cue. Thus, it is quite possible that TD children have superior speech perception abilities as compared to children with 
SSD (Munson, Baylis, Krause, \& Yim, 2009; Munson, Kurtz, et al., 2005). For example, Munson et al. (2009) reported that children with phonological disorders have an inability to accurately encode acoustic-perceptual input, which would then be used to form incorrect phonological representations due to the inaccurate perceptual encoding.

Moreover, the possibility that children with SSD have speech perception deficits is consistent with one model of speech production, the DIVA model (Guenther, Hampson, \& Johnson, 1998; Guenther, 1995; Perkell et al., 2000), that suggests that sensory representations, including acoustic/perceptual representations are accessed as the targets for speech production. Thus, deficits in acoustic-perceptual encoding/processing may be the source of speech production problems in children with SSD (Munson et al., 2009). If children are unable to adequately encode acoustic information in order to create a detailed phonological representation, then they will be unable to accurately produce a word since the accessible underlying phonological information is not correct (Edwards \& Lahey, 1998).

In other words, deficits in acoustic-perceptual encoding/processing may be the source of speech production problems in children with SSD (Guenther et al., 1998; Guenther, 1995; Munson et al., 2009; Perkell et al., 2000). That is, if the children have difficulty encoding auditory information, this will result in an incorrect phonological representation; then when children go to produce a word, they will retrieve the wrong phonological information, resulting in an inaccurate word production (Edwards \& Lahey, 1998; Locke \& Kutz, 1975).

In comparison to their TD peers, do children with SSD have similar cumulative measures of language and motor planning processes, as measured by NRT verbal response time? The present study incorporated verbal RTs to provide a cumulative measure all of the cognitive, linguistic, and motor planning processes preceding the production of a nonword. Interestingly, the median 
RTs of the children with SSD were significantly faster than the TD children. Moreover, the fast RTs of the children with SSD were linked to their less accurate phonetic articulation accuracy of the target NRT consonants: Higher accuracy measures were correlated with slower RTs. Thus by responding so quickly, the children with SSD potentially did not allow themselves the time to accurately encode all of the phonetic information, which then impacted the accuracy of their responses, both in terms of overall PCC as well as in the binary features of the speech sounds (place, manner, and voicing). Moreover, the correlation results found that the children who had better speech production (both on the NRT and GFTA-2) and receptive vocabulary skills also had slower NRT verbal RTs.

Neuroimaging data has shown that adults who are better nonword-repeaters engage more processing resources at the time of encoding the auditory information of nonwords than poor nonword repeaters ${ }^{4}$ (Barry, Sabisch, Friederici, \& Brauer, 2011). Interpreting Barry and colleagues (2011) finding within the scope of the present study, for this group of children, slower RTs quite possibly indicated that more processing resources were engaged and utilized due to the higher cognitive demands. In other words, the RT data provide further evidence that children with SSD, who are less accurate nonword producers than their TD peers, could also have less efficient phonological encoding processes.

Moreover, Barry and colleagues (2011) found covert rehearsal to be a support strategy to compensate for less efficient auditory encoding processes during nonword repetition (Barry et al., 2011). Thus, another interpretation of the fast RTs of the children with SSD is that they did not have access to, or had not yet developed, the ability to use covert rehearsal strategies.

Without the ability to covertly practice and rehearse the nonwords, these children immediately started (often incorrectly) repeating the words. While covert or subvocal rehearsal is a strategy

\footnotetext{
4 This assumes that stronger neural activation corresponds to higher processing demands.
} 
that does not emerge until around the age of 7 years (Coady \& Evans, 2008; Gathercole, Alloway, Willis, \& Adams, 2006; Gathercole \& Baddeley, 1990; Gathercole, 2006), it is possible that the TD children utilized some rudimentary subvocal rehearsal strategies during their productions. Alternatively, the significantly faster RTs of the children with SSD suggest that instead of using a more advanced subvocal rehearsal strategy, the children instead opted to verbally produce the words as quickly as they perceived them. And anecdotally, this was indeed the case, as many children with SSD started producing their nonwords even before the computer had finished presenting the word.

Do sounds that are produced correctly and incorrectly in real words on a standardized speech assessment predict sound accuracy on the NRT? To take the speech errors of both groups of children into account, the GFTA-2/NRT PCC Predictor measure was created. The GFTA2/NRT PCC Predictor measure identified possible speech production errors children might have with the targeted NRT sounds by examining the children's production of those same sounds, in the same word position, on the GFTA-2. Thus, this measure was designed to be an ideal measure of how children could perform on the NRT, if the task only required speech production skills.

When children's basic speech production skills were taken into account by the GFTA-2/NRT PCC Predictor measure, the group differences were greatly reduced. Children with SSD were still less accurate in their nonword productions, though they were much closer in comparison with the TD children. Thus, it would appear that the children with SSD had additional deficits, beyond speech articulation, that affected their NRT performance. Based on the other analyses of the data, one potential deficit could be phonological encoding.

While the end result of both the GFTA-2 and NRT is the production of a word (real or nonsense), the tasks have some inherent differences, which may account for some of the 
performance differences observed during the actual production of the NRT and the predicted NRT outcomes via GFTA-2 performance. To clarify, picture naming, such as what occurred during the GFTA-2, involves many cognitive processes: visual perception and recognition, conceptual and semantic processing, lexical access, phonological form encoding, and the planning and execution of speech articulation (Dell, 1986; Levelt, 1999). Alternatively, as discussed previously, different levels of information processing are necessary for NRT perception and production (Aslin \& Smith, 1988; Bowey, 1996, 2006; Coady \& Evans, 2008; Gathercole \& Baddeley, 1997; Gathercole, 2006) including speech perception, phonological encoding, phonological memory, phonological assembly, and articulation.

While both the GFTA-2 and the NRT both require phonological form encoding and articulation of words, they differ in whether or not lexical representations are accessed and/or used (Vance, Stackhouse, \& Wells, 2005). The GFTA-2 picture-naming task required the children to access their own existing motor programs to produce each word; thus, previously stored phonological, semantic, and lexical information was accessed and used to produce the words. Alternatively, the children did not have existing phonological representations or motor programs for the NRT words; thus, information about the nonwords needed to come from the speech input that was subsequently stored in phonological short-term memory (Vance et al., 2005). The fact that the children produced certain phonemes correctly on the GFTA-2 but not on the NRT could be indicative of the additional short-term memory load required to hold a novel string of phonemes in memory, as compared to familiar known words (Gathercole et al., 1994; Vance et al., 2005).

Finally at a basic level, a clear difference between the NRT and the GFTA- 2 is that the former requires accurate acoustic-auditory speech perception, while the latter does not. Thus, 
another interpretation for the fact that speech articulation ability of sounds in familiar real words did not fully predict production of nonwords is that the speech perception abilities of children with SSD and TD children differ. Thus, as discussed in detail above, it is quite possible that TD children have superior speech perception abilities as compared to children with SSD (Munson et al., 2009; Munson, Kurtz, et al., 2005).

Caveats and directions for future research. While this study provides new and interesting information regarding the underlying mechanisms of SSD, there are some possible caveats to the findings. First, the sample of children was not extremely large. Further assessment with a much larger group of children will be necessary to ensure that these findings are consistent. While some previous studies examining the utility of nonword repetition tasks have used similar sized samples (e.g., 16 in each group) (Munson, Edwards, et al., 2005), other studies have used much larger samples of children (e.g., 179-581 children) (Archibald \& Joanisse, 2009; Ellis Weismer et al., 2000; Shriberg et al., 2009) that potentially provide more accurate information due to the inherent regression to the mean that occurs when a larger population is sampled.

This study is also fairly narrow in scope, in that it focused on the phonological encoding and articulation of nonwords. Other proposed required stages of nonword repetition, such as speech perception and short-term memory (Coady \& Evans, 2008), were not specifically addressed in the present study. Given Munson and colleagues' $(2005,2009)$ suggestion that children with SSD primarily have difficulties adequately perceiving acoustic-auditory information, future studies incorporating speech perception tasks that directly and indirectly relate to nonword repetition will provide more information to support or reject this claim. In addition, no memory tasks or assessments were used in this study, leaving this as an avenue for future research. 
Just as the NRT has proven to be useful in identifying children with language impairments (D. V. M. Bishop et al., 2006; Botting \& Conti-Ramsden, 2001; Conti-Ramsden et al., 2001; Dollaghan \& Campbell, 1998; Ellis Weismer et al., 2000; Gathercole \& Baddeley, 1990; Gathercole et al., 1994; Gathercole, 2006; Graf Estes et al., 2007; Grant et al., 1997; Gray, 2003; Kamhi \& Catts, 1986; Laws \& Gunn, 2004; Marton \& Schwartz, 2003; Montgomery, 2004), it might also be a tool that can help speech-language pathologists (SLPs) identify deficits in children with SSD. Speech production deficits are typically measured during the assessment of children with SSD, and the children's speech production errors are then eventually targeted in treatment. However, children's ability to perceive and encode speech sounds is rarely, if ever, addressed by SLPs.

Given that the NRT is a cheap tool that is easy to administer and score, it could potentially be an excellent addition to assessment procedures in order to provide SLPs with basic information related to children's ability to perceive and encode speech sounds ${ }^{5}$. Based on the data from the present study, it would appear that when children with SSD have low production accuracy and/or fast verbal responses on the NRT, one possible interpretation is that they also have a phonological encoding deficit, along with their speech production impairment. However, in order for a SLP to more accurately make that assumption, a child would also have to perform below average on an additional articulation/phonology test (i.e., ruling in a SSD diagnosis) while performing within the normal range on language tests (i.e., ruling out a language impairment diagnosis $)^{6}$.

\footnotetext{
${ }^{5}$ It is acknowledged that the NRT cannot provide the detail of other research-based phonological encoding tasks, such as the cross-modal picture-word interference task (Brooks \& MacWhinney, 2000). However, for clinical application, it might offer enough information for SLPs so that they know to plan for perception/encoding-related activities in treatment.

${ }^{6}$ If the child did poorly on the NRT and also scored below the normal range on standardized language tests, then interpreting the NRT performance in terms of speech ability would be much more difficult, if not impossible. The
} 
If a child with SSD was identified as having a having a potential deficit in phonological encoding based on performance on the NRT, then subsequent treatment of the SSD should contain activities that address phonological encoding through speech perception tasks, as well as the traditional treatment that would address the speech production issues. In the end, it is quite likely that children with SSD have inaccurate perception of speech sounds (Chaney, 1988; Macken, 1980; McGregor \& Schwartz, 1992; Munson, Edwards, et al., 2005), which then negatively affect their speech production abilities (Edwards \& Lahey, 1998; Guenther et al., 1998; Guenther, 1995; Kluender \& Lotto, 1999; Munson et al., 2009; Perkell et al., 2000; Scott, 2012). Thus, in order to effectively treat children with SSD, children's speech perception and phonological encoding abilities must also be addressed both in assessment and treatment.

\section{Conclusion}

The NRT was used to identify possible deficits children with SSD might have, specifically in terms of phonological encoding. Children with SSD were less accurate in their repetition of unfamiliar nonwords than TD children even after their speech sound production ability was taken into account, suggesting that a deficit beyond simple speech articulation was affecting their performance. Children with SSD demonstrated phonological encoding difficulties, as their ability to accurately produce the place of articulation of a consonant was more impaired than their ability to represent the manner and voicing phonetic characteristics. In addition, children with SSD demonstrated much faster verbal response times than did their typical peers, though more accurate NRT responses were correlated with slower verbal response times. These results suggest that children with SSD may have phonological encoding deficits, which might negatively impact their ability to accurately produce speech sounds. The NRT could be used to 
help identify underlying mechanisms of SSD, such a deficit in phonological encoding, which could lead to more effective treatment approaches.

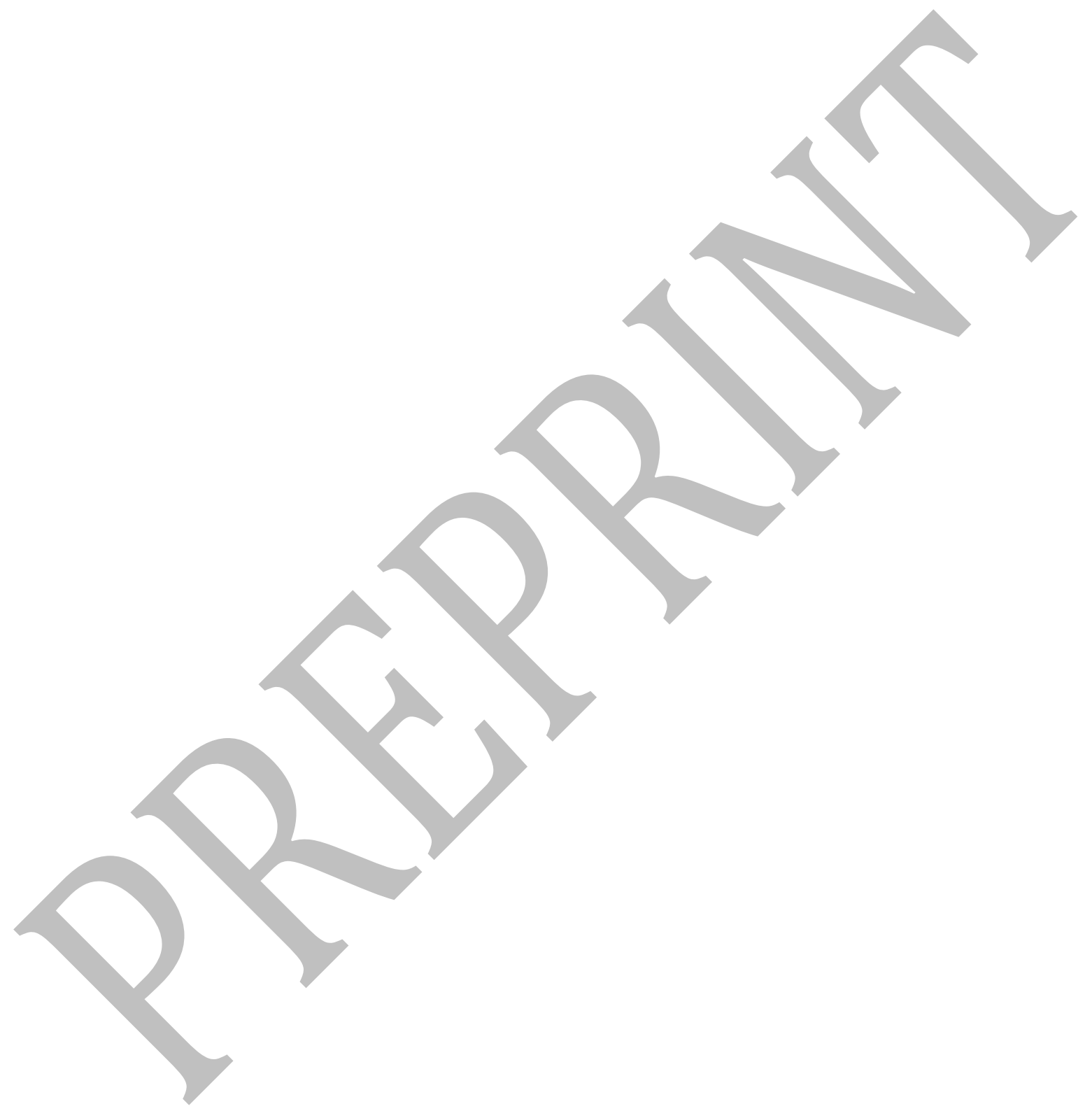




\section{References}

American National Standards Institute. (1991). American national standard specifications for audiometers (ANSI S3.6-1969). New York: ANSI.

Archibald, L. M. D., \& Gathercole, S. E. (2006). Nonword repetition: a comparison of tests. Journal of Speech, Language, and Hearing Research: JSLHR, 49(5), 970-983. doi:10.1044/1092$4388(2006 / 070)$

Archibald, L. M. D., \& Joanisse, M. F. (2009). On the sensitivity and specificity of nonword repetition and sentence recall to language and memory impairments in children.Journal of Speech, Language, and Hearing Research: JSLHR, 52(4), 899-914. doi:10.1044/1092-4388(2009/080099)

Aslin, R. N., \& Smith, L. B. (1988). Perceptual development. Annual Review of Psychology, 39, 435473. doi:10.1146/annurev.ps.39.020188.002251

Barlow, J. A. (2003). The Assessment of English Phonology (AEP). San Diego, CA: San Diego State Universit.

Barry, J. G., Sabisch, B., Friederici, A. D., \& Brauer, J. (2011). Encoding: the keystone to efficient functioning of verbal short-term memory. Neuropsychologia, 49(13), 3636-3647. doi:10.1016/j.neuropsychologia.2011.09.018

Bishop, D. V. M., Adams, C. V., \& Norbury, C. F. (2006). Distinct genetic influences on grammar and phonological short-term memory deficits: evidence from 6-year-old twins. Genes, Brain and Behavior, 5(2), 158-169. doi:10.1111/j.1601-183X.2005.00148.x

Bishop, D. V. M., North, T., \& Donlan, C. (1996). Nonword repetition as a behavioural marker for inherited language impairment: evidence from a twin study. Journal of Child Psychology and Psychiatry, and Allied Disciplines, 37(4), 391-403.

Bleile, K. M. (2006). The late eight. San Diego: Plural Pub. 
Botting, N., \& Conti-Ramsden, G. (2001). Non-word repetition and language development in children with specific language impairment (SLI). International Journal of Language \& Communication Disorders / Royal College of Speech \& Language Therapists, 36(4), 421-432.

Bowey. (1996). On the Association between Phonological Memory and Receptive Vocabulary in Five-Year-Olds. Journal of Experimental Child Psychology, 63(1), 44-78.

Bowey, J. A. (2006). Clarifying the phonological processing account of nonword repetition. Applied Psycholinguistics, 27(04), 548-552. doi:10.1017/S0142716406220393

Brooks, P. J., \& MacWhinney, B. (2000). Phonological priming in children’s picture naming. Journal of Child Language, 27(2), 335-366.

Chaney, C. (1988). Identification of Correct and Misarticulated Semivowels. Journal of Speech and Hearing Disorders, 53(3), 252-261.

Coady, J. A., \& Evans, J. L. (2008). Uses and interpretations of non-word repetition tasks in children with and without specific language impairments (SLI). International Journal of Language \& Communication Disorders / Royal College of Speech \& Language Therapists, 43(1), 1-40. doi:10.1080/13682820601116485

Conti-Ramsden, G., Botting, N., \& Faragher, B. (2001). Psycholinguistic markers for specific language impairment (SLI). Journal of Child Psychology and Psychiatry, and Allied Disciplines, 42(6), $741-748$.

Dell, G. S. (1986). A spreading-activation theory of retrieval in sentence production. Psychological Review, 93(3), 283-321. doi:10.1037/0033-295X.93.3.283

Dinnsen, D. A., Chin, S. B., Elbert, M., \& Powell, T. W. (1990). Some constraints on functionally disordered phonologies: phonetic inventories and phonotactics. Journal of Speech and Hearing Research, 33(1), 28-37.

Dollaghan, C. A., \& Campbell, T. F. (1998). Nonword Repetition and Child Language Impairment. Journal of Speech, Language, and Hearing Research, 41(5), 1136-1146. 
Dunn, L., \& Dunn, D. (2007). Peabody Picture Vocabulary Test - 4th ed. (4th ed.). Circle Pines, MN: American Guidance Service Publishing/Pearson Assessments.

Edwards, J., Beckman, M. E., \& Munson, B. (2004). The interaction between vocabulary size and phonotactic probability effects on children's production accuracy and fluency in nonword repetition. Journal of Speech, Language, and Hearing Research: JSLHR, 47(2), 421-436. doi:10.1044/1092-4388(2004/034)

Edwards, J., \& Lahey, M. (1998). Nonword repetitions of children with specific language impairment: Exploration of some explanations for their inaccuracies. Applied Psycholinguistics, 19(02), 279-309. doi:10.1017/S0142716400010079

Ellis Weismer, S., Tomblin, J. B., Zhang, X., Buckwalter, P., Chynoweth, J. G., \& Jones, M. (2000). Nonword repetition performance in school-age children with and without language impairment. Journal of Speech, Language, and Hearing Research: JSLHR, 43(4), 865-878.

Gathercole, S. E. (2006). Nonword repetition and word learning: The nature of the relationship. Applied Psycholinguistics, 27(04), 513-543. doi:10.1017/S0142716406060383

Gathercole, S. E., \& Baddeley, A. D. (1990). Phonological memory deficits in language disordered children: Is there a causal connection? Journal of Memory and Language, 29(3), 336-360. doi:10.1016/0749-596X(90)90004-J

Gathercole, S. E., \& Baddeley, A. D. (1997). Sense and sensitivity in phonological memory and vocabulary development: a reply to Bowey (1996). Journal of Experimental Child Psychology, 67(2), 290-294; discussion 295-301. doi:10.1006/jecp.1997.2391

Gathercole, S. E., \& Hitch, G. J. (1993). Developmental Changes in Short-Term Memory: A Revised Working Memory Perspective. In A. Collins, S. Gathercole, M. A. Conway, \& P. E. Morris (Eds.), Theories of Memory (pp. 1-189). Lawrence Erlbaum. 
Gathercole, S. E., Willis, C. S., Baddeley, A. D., \& Emslie, H. (1994). The children's test of nonword repetition: A test of phonological working memory. Memory, 2(2), 103-127. doi:10.1080/09658219408258940

Gierut, J. A. (1998). Treatment efficacy: functional phonological disorders in children. Journal of Speech, Language, and Hearing Research: JSLHR, 41(1), S85-100.

Gierut, J. A., Simmerman, C. L., \& Neumann, H. J. (1994). Phonemic structures of delayed phonological systems. Journal of Child Language, 21(2), 291-316.

Goldman, R., \& Fristoe, M. (2000). Goldman-Fristoe Test of Articulation, 2nd ed. Minneapolis, MN: Pearson.

Graf Estes, K., Evans, J. L., \& Else-Quest, N. M. (2007). Differences in the nonword repetition performance of children with and without specific language impairment: a meta-analysis. Journal of Speech, Language, and Hearing Research: JSLHR, 50(1), 177-195. doi:10.1044/1092-4388(2007/015)

Grant, J., Karmiloff-Smith, A., Gathercole, S. E., Paterson, S., Howlin, P., Davies, M., \& Udwin, O. (1997). Phonological Short-term Memory and its Relationship to Language in Williams Syndrome. Cognitive Neuropsychiatry, 2(2), 81-99. doi:10.1080/135468097396342

Gray, S. (2003). Diagnostic accuracy and test-retest reliability of nonword repetition and digit span tasks administered to preschool children with specific language impairment. Journal of Communication Disorders, 36(2), 129-151. doi:10.1016/S0021-9924(03)00003-0

Guenther, F. H. (1995). Speech sound acquisition, coarticulation, and rate effects in a neural network model of speech production. Psychological Review, 102(3), 594-621.

Guenther, F. H., Hampson, M., \& Johnson, D. (1998). A theoretical investigation of reference frames for the planning of speech movements. Psychological Review, 105(4), 611-633.

Hartsuiker, R. J., Bastiaanse, R., Postma, A., \& Wijnen, F. (2005). Phonological encoding and monitoring in normal and pathologicla speech. Hove, UK: Psychology Press. 
Hresko, W., Reid, K., \& Hammill, D. (1999). Test of Early Language Development, 3rd ed. (TELD-3). Austin, TX: PRO-ED.

Kamhi, A. G., \& Catts, H. W. (1986). Toward an understanding of developmental language and reading disorders. The Journal of Speech and Hearing Disorders, 51(4), 337-347.

Kluender, K. R., \& Lotto, A. J. (1999). Virtues and perils of an empiricist approach to speech perception. The Journal of the Acoustical Society of America, 105(1), 503-511. doi:10.1121/1.424587

Krishnan, S., Alcock, K. J., Mercure, E., Leech, R., Barker, E., Karmiloff-Smith, A., \& Dick, F. (2013). Articulating novel words: children's oromotor skills predict non-word repetition abilities. Journal of Speech, Language, and Hearing Research: JSLHR. doi:10.1044/1092$4388(2013 / 12-0206)$

Laws, G., \& Gunn, D. (2004). Phonological memory as a predictor of language comprehension in Down syndrome: a five-year follow-up study. Journal of Child Psychology and Psychiatry, and Allied Disciplines, 45(2), 326-337.

Levelt. (1999). Models of word production. Trends in Cognitive Sciences, 3(6), 223-232.

Locke, J. L., \& Kutz, K. J. (1975). Memory for speech and speech for memory. Journal of Speech and Hearing Research, 18(1), 176-191.

Macken, M. A. (1980). The child's lexical representation: the “puzzle-puddle-pickle” evidence. Journal of Linguistics, 16(01), 1-17. doi:10.1017/S0022226700006307

Marton, K., \& Schwartz, R. G. (2003). Working memory capacity and language processes in children with specific language impairment. Journal of Speech, Language, and Hearing Research: JSLHR, 46(5), 1138-1153.

McGregor, K. K., \& Schwartz, R. G. (1992). Converging evidence for underlying phonological representation in a child who misarticulates. Journal of Speech and Hearing Research, 35(3), $596-603$. 
Montgomery, J. (2004). Sentence comprehension in children with specific language impairment:

effects of input rate and phonological working memory. International Journal of Language \& Communication Disorders / Royal College of Speech \& Language Therapists, 39(1), 115-133. doi:10.1080/13682820310001616985

Munson, B., Baylis, A. L., Krause, M. O., \& Yim, D. (2009). Representation and access in phonological impairment. In C. Fougeron (ed.), Papers in laboratory phonology 10: Variation, detail, and representaiton. N: Mouton de Gruyter.

Munson, B., Edwards, J., \& Beckman, M. E. (2005). Relationships between nonword repetition accuracy and other measures of linguistic development in children with phonological disorders. Journal of Speech, Language, and Hearing Research: JSLHR, 48(1), 61-78.

Munson, B., Kurtz, B. A., \& Windsor, J. (2005). The influence of vocabulary size, phonotactic probability, and wordlikeness on nonword repetitions of children with and without specific language impairment. Journal of Speech, Language, and Hearing Research: JSLHR, 48(5), 1033-1047. doi:10.1044/1092-4388(2005/072)

Perkell, J. S., Guenther, F. H., Lane, H., Matthies, M. L., Perrier, P., Vick, J., ... Zandipour, M. (2000). A theory of speech motor control and supporting data from speakers with normal hearing and with profound hearing loss. Journal of Phonetics, 28(3), 233-272. doi:10.1006/jpho.2000.0116

Robbins, J., \& Klee, T. (1987). Clinical Assessment of Oropharyngeal Motor Development in Young Children. Journal of Speech and Hearing Disorders, 52(3), 271-277.

Roid, G., \& Miller, L. (1997). Leiter International Performance Scale - Revised (Leiter-R). Wood Dale, IL: Stoelting.

Sasisekaran, J., \& Byrd, C. (2013). Nonword repetition and phoneme elision skills in school-age children who do and do not stutter. International Journal of Language \& Communication 
Disorders / Royal College of Speech \& Language Therapists, 48(6), 625-639.

doi:10.1111/1460-6984.12035

Scott, S. K. (2012). The neurobiology of speech perception and production--can functional imaging tell us anything we did not already know? Journal of Communication Disorders, 45(6), 419425. doi:10.1016/j.jcomdis.2012.06.007

Shriberg, L. D. (1993). Four new speech and prosody-voice measures for genetics research and other studies in developmental phonological disorders. Journal of Speech and Hearing Research, 36(1), 105-140.

Shriberg, L. D., Austin, D., Lewis, B. A., McSweeny, J. L., \& Wilson, D. L. (1997). The percentage of consonants correct (PCC) metric: extensions and reliability data.Journal of Speech, Language, and Hearing Research: JSLHR, 40(4), 708-722.

Shriberg, L. D., \& Kwiatkowski, J. (1982). Phonological disorders III: a procedure for assessing severity of involvement. The Journal of Speech and Hearing Disorders, 47(3), 256-270.

Shriberg, L. D., Lohmeier, H. L., Campbell, T. F., Dollaghan, C. A., Green, J. R., \& Moore, C. A. (2009). A nonword repetition task for speakers with misarticulations: the Syllable Repetition Task (SRT). Journal of Speech, Language, and Hearing Research: JSLHR, 52(5), 1189-1212. doi:10.1044/1092-4388(2009/08-0047)

Thal, D. J., Miller, S., Carlson, J., \& Vega, M. M. (2005). Nonword repetition and language development in 4-year-old children with and without a history of early language delay. Journal of Speech, Language, and Hearing Research: JSLHR, 48(6), 1481-1495. doi:10.1044/1092-4388(2005/103)

Van Riper, C., \& Irwin, J. (1958). Voice and articulation. Englewood Cliffs, NJ: Prentice-Hall. Vance, M., Stackhouse, J., \& Wells, B. (2005). Speech-production skills in children aged 3-7 years. International Journal of Language \& Communication Disorders / Royal College of Speech \& Language Therapists, 40(1), 29-48. 
Wells, B. (1995). Phonological considerations in repetition tests. Cognitive Neuropsychology, 12(8), 847-855. doi:10.1080/02643299508251404

Yoss, K. A., \& Darley, F. L. (1974). Developmental Apraxia of Speech in Children with Defective Articulation. Journal of Speech and Hearing Research, 17(3), 399-416.

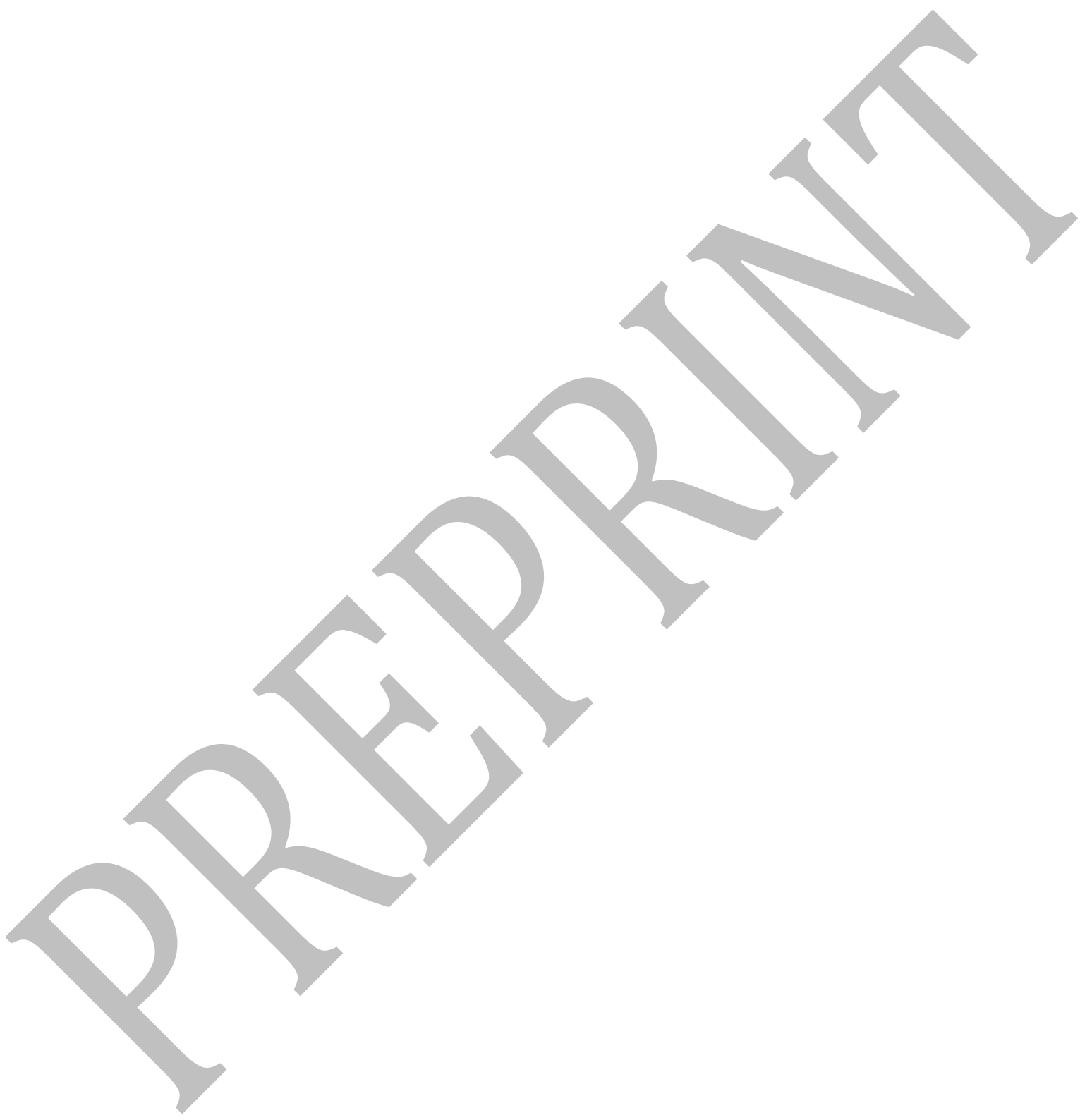


Appendix A. List of the NRT consonants produced in error at least twice on the Goldman Fristoe Test of Articulation $-2^{\text {nd }}$ ed. (GFTA-2) for the children with speech sound disorders (SSD).

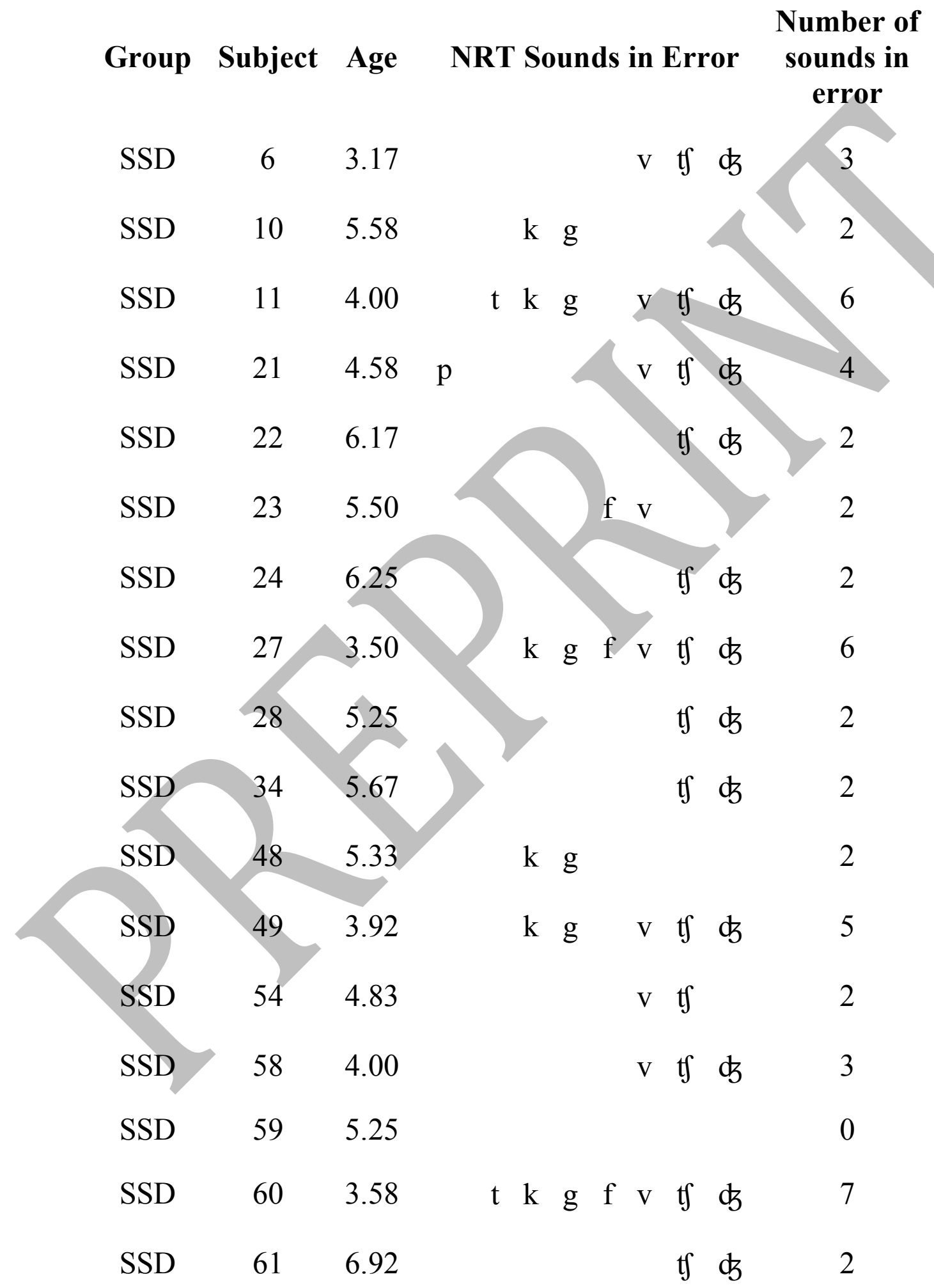




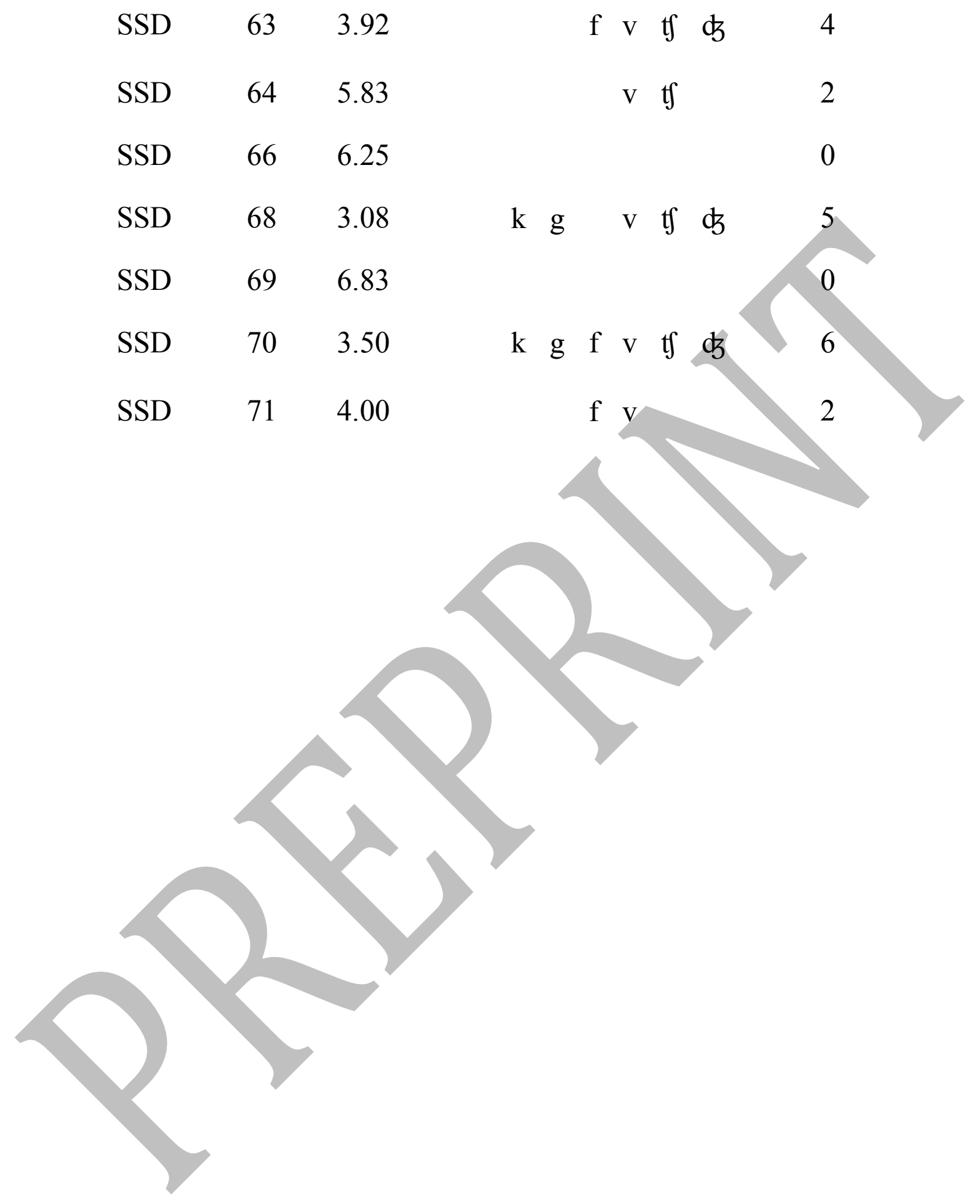


Appendix B. List of the NRT consonants produced in error at least twice on the Goldman Fristoe Test of Articulation $-2^{\text {nd }}$ ed. (GFTA-2) for the typically developing (TD) children.

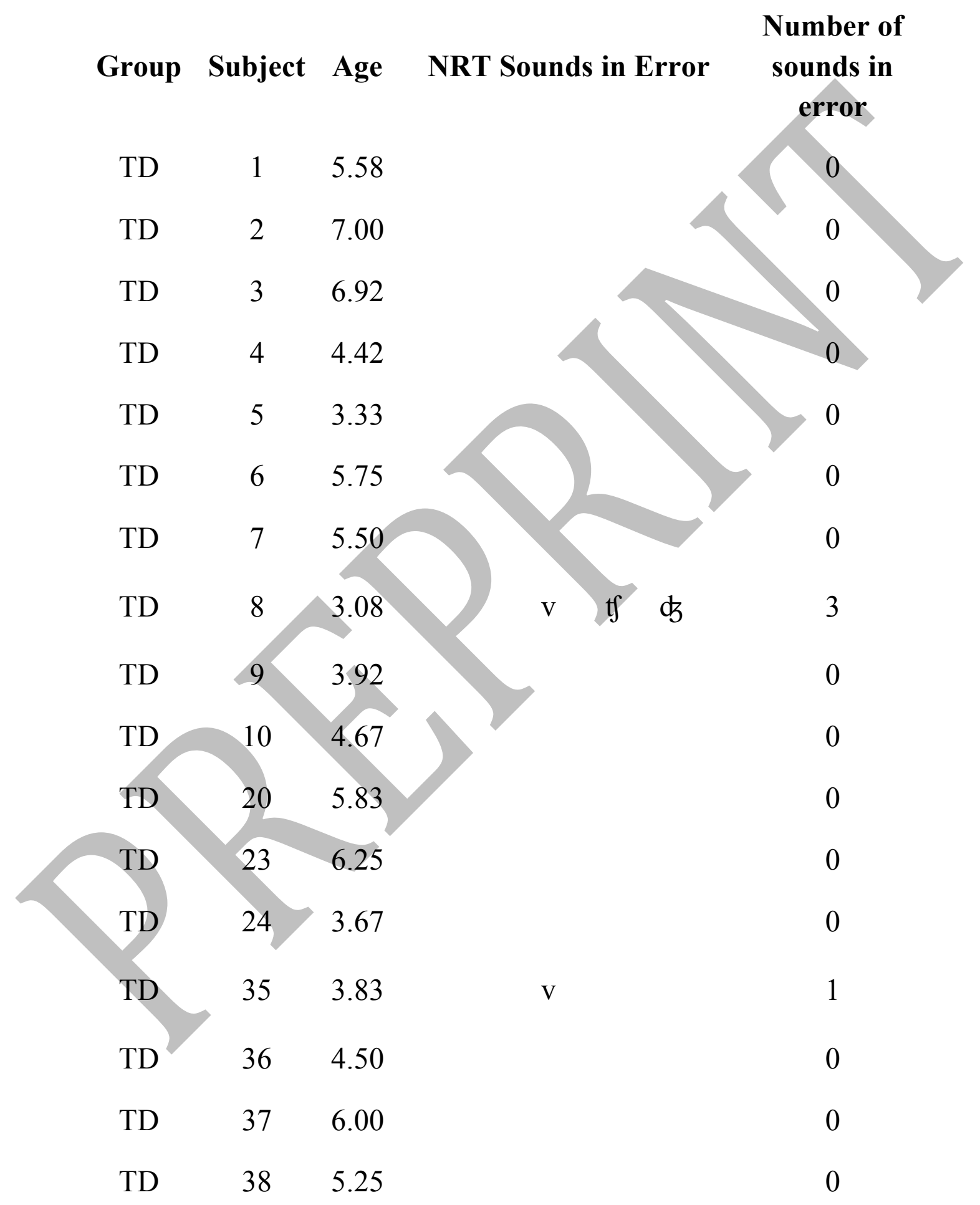




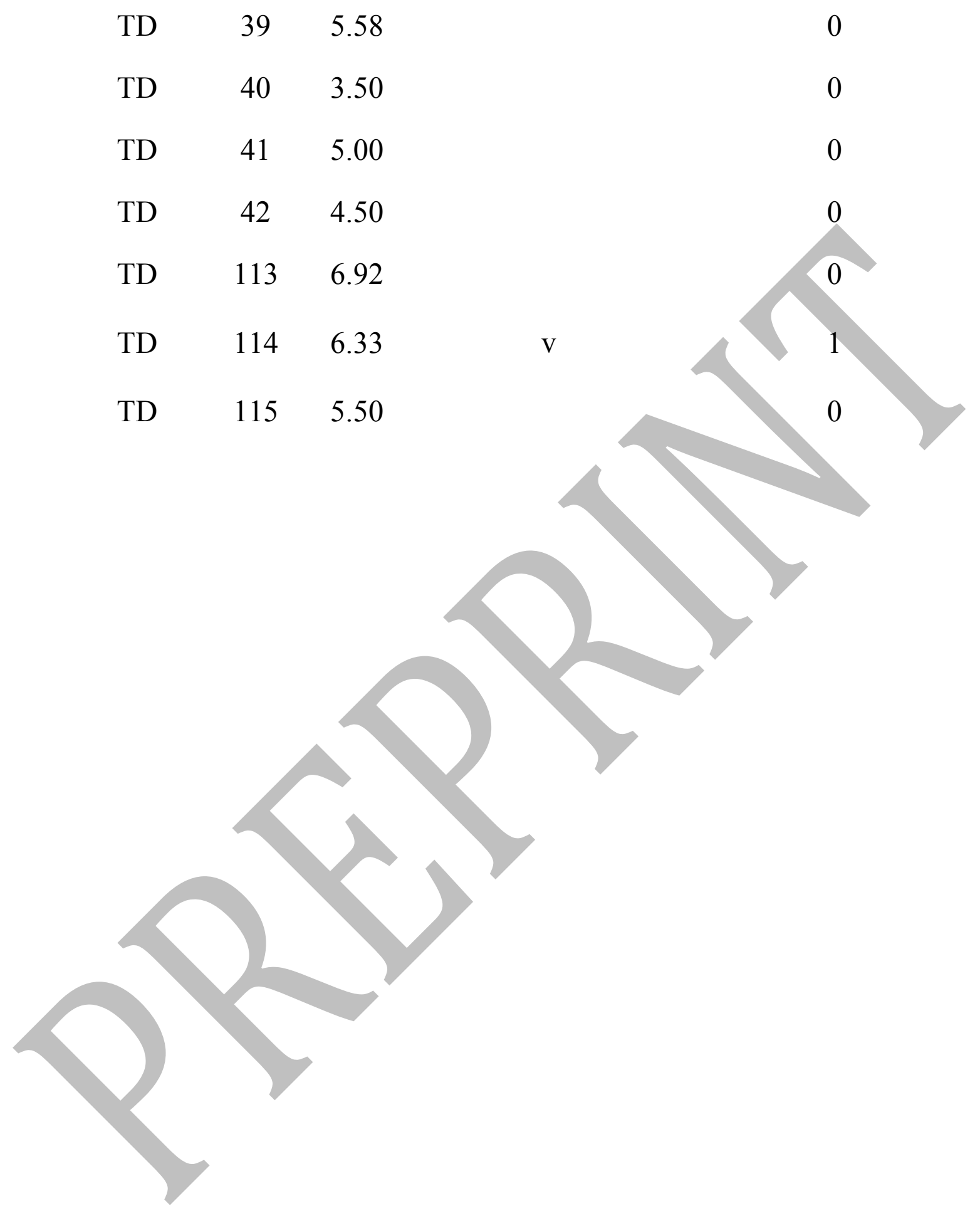


Table 1. Characteristics of the SSD and TD subject samples

\begin{tabular}{|c|c|}
\hline & $\operatorname{SSD}(n=24)$ \\
\hline Assessment Age: Mean (SD) & $\begin{array}{ccc}5.13(1.18) & 4.87(1.18) \\
\mathrm{t}(46)=0.782, \quad \mathfrak{p}>43\end{array}$ \\
\hline GFTA-2 Standard Score & $\begin{array}{c}106.00(6.83) \\
\mathrm{t}(46)=14.425, \mathrm{p}<.0001\end{array}$ \\
\hline GFTA-2 Percentile Score & $\begin{array}{c}53.04(18.05) \\
t(46)=11.991, p<.0001\end{array}$ \\
\hline $\begin{array}{l}\text { GFTA-2 Raw Score } \\
\text { (i.e., number of errors) }\end{array}$ & 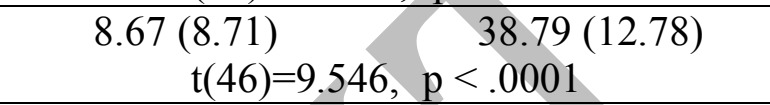 \\
\hline $\begin{array}{c}\text { Number of consonants occurring on the NRT } \\
\text { that were in error on the GFTA-2 } \\
\text { (out of } 11 \text { possible consonants) }\end{array}$ & $\begin{array}{c}0.21(0.66) \\
t(46)=6.432, p<.0001\end{array}$ \\
\hline PPVT-IV Standard Score & $\begin{array}{c}113.13(12.48) \\
t(46)=2.807, p<.06\end{array}$ \\
\hline Leiter-R Standard Score & $106.83(14.40)$ \\
\hline TELD-3 SLQ Standard Score & $102.92(12.06)$ \\
\hline Hearing & Within normal limits \\
\hline
\end{tabular}

- The Goldman Fristoe Test of Articulation -2 (GFTA-2; Goldman \& Fristoe, 2000), Peabody Picture Vocabulary Test - IV (PPVT-IV; Dunn \& Dunn, 1997), Test of Early Language Development - 3 (TELD-3; Hresko et al., 1999) and Leiter International Performance Scale - Revised (Leiter-R; Levine, 1997) yield standard scores with M=100 and $\mathrm{SD}=15$.

- The TELD-3 Spoken Language Quotient (SLQ) has Receptive Language and Expressive Language measures assessing semantics, morphology, syntax, and sentence memory. 
Table 2. Nonword Repetition Task (NRT) phonetic articulation percentage accuracy (SEM) for children with SSD and TD children for the consonant binary features of place, manner, and voicing of articulation.

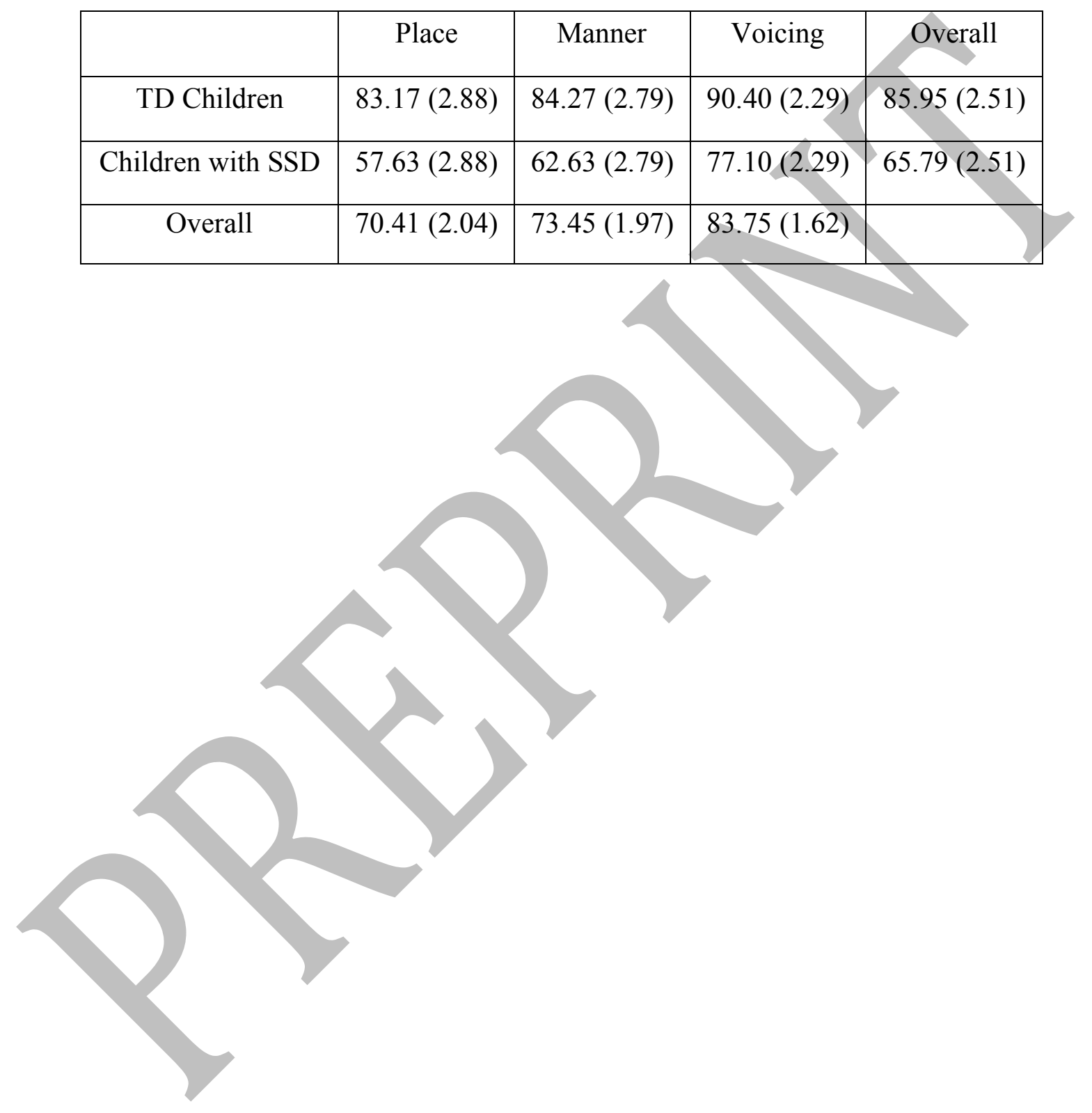


Table 3. Median Nonword Repetition Task (NRT) verbal response times (RT) in ms (SD) for children with SSD and TD children for each of the four syllable lengths of the NRT, as well as an overall RT measurement.

\begin{tabular}{|c|c|c|c|c|c|}
\hline & One Syllable & Two Syllable & Three Syllable & Four Syllable & Overall \\
\hline TD Children & $1211(385)$ & $1322(257)$ & $1930(343)$ & $2270(446)$ & $1683(309)$ \\
\hline Children with SSD & $1039(169)$ & $1116(218)$ & $1554(295)$ & $1911(450)$ & $1405(313)$ \\
\hline Overall & $1125(307)$ & $1219(258)$ & $1742(369)$ & $2090(446)$ & \\
\hline
\end{tabular}




\section{Figure Captions}

Figure 1. Four Nonword Repetition Task (NRT) accuracy measures for typically developing (TD) children and children with speech sound disorders (SSD): Percent Consonants Correct (PCC), Consonant Place of Articulation, Consonant Manner of Articulation, and Consonant Voicing. Children with SSD were predictably less accurate than the TD children on all measures. In addition, while the TD children did not differ in their consonant place and manner accuracy measures, the children with SSD were less accurate in their production of consonant place of articulation as compared to the manner of articulation, suggesting an impairment in phonological encoding.

Figure 2. NRT verbal response times (RTs) by syllable length for TD children and children with SSD. Children with SSD produced significantly faster overall RTs; their RTs for two, three, and four syllable nonwords were also faster than the TD children's responses.

Figure 3. Scatterplots showing the correlational relationship between the NRT verbal response times (RTs) and NRT accuracy measures for TD children and children with SSD: A) Percent Consonants Correct (PCC), B) Consonant Place of Articulation, and C) Consonant Manner of Articulation.

Figure 4. Scatterplots showing the correlational relationship between the NRT verbal response times (RTs) and standardized test measures (standard scores) for TD children and children with SSD: A) Goldman-Fristoe Test of Articulation $-2^{\text {nd }}$ Ed. (Goldman \& Fristoe, 2000), B) Peabody Picture Vocabulary Test $-4^{\text {th }}$ Ed. (Dunn \& Dunn, 2007). 


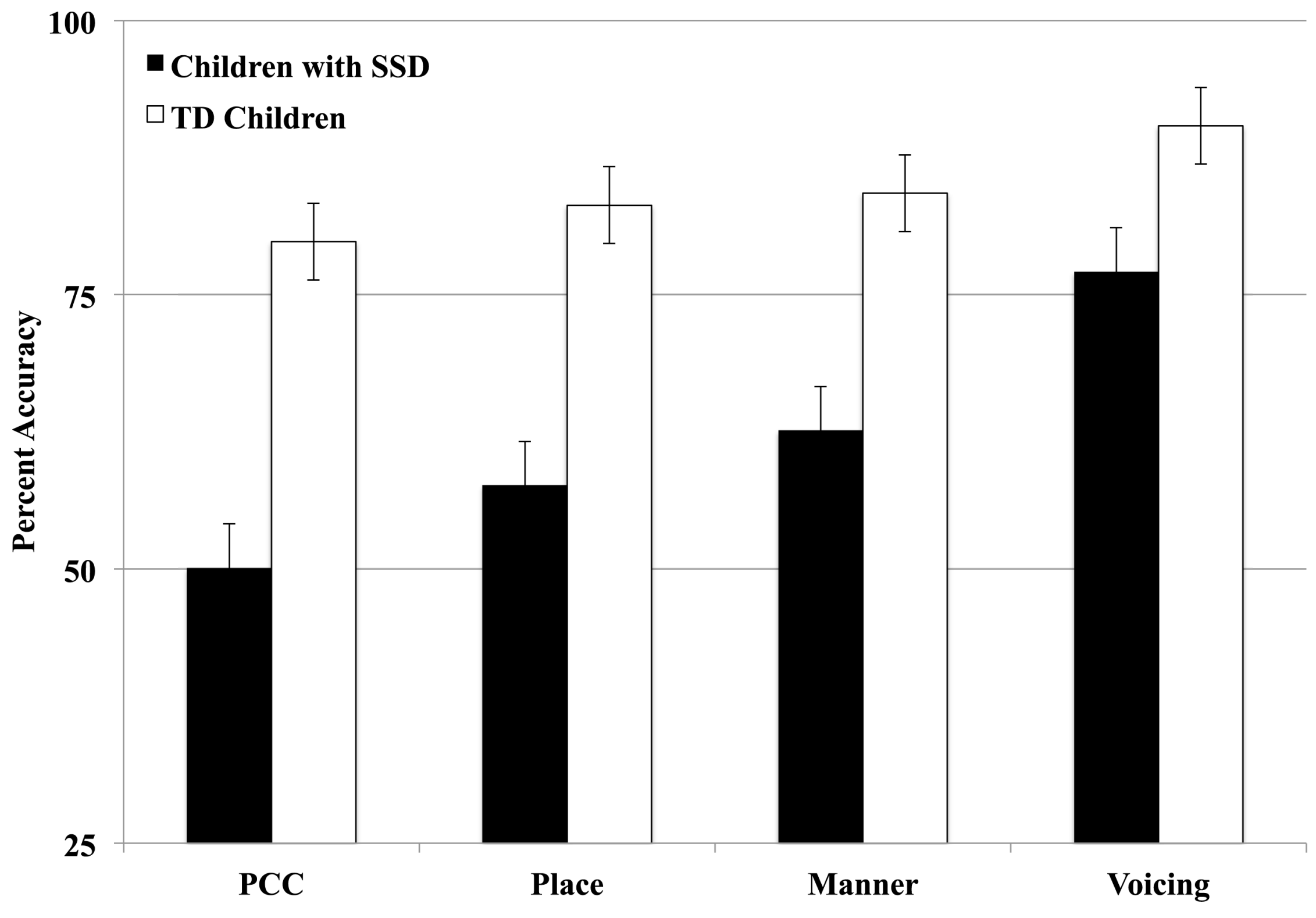




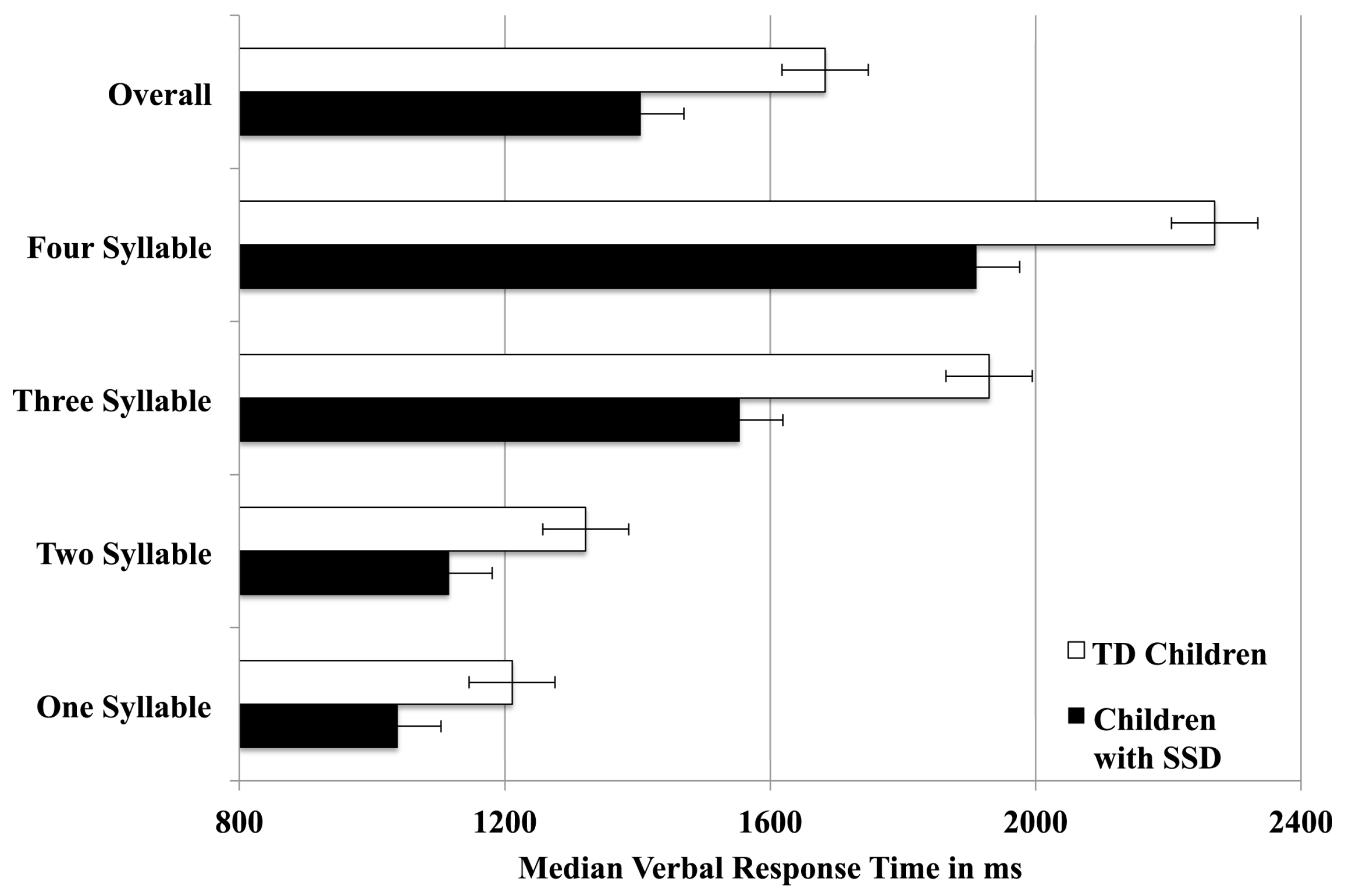


A. Percent Consonants Correct (PCC) x Overall Median Verbal Response Time

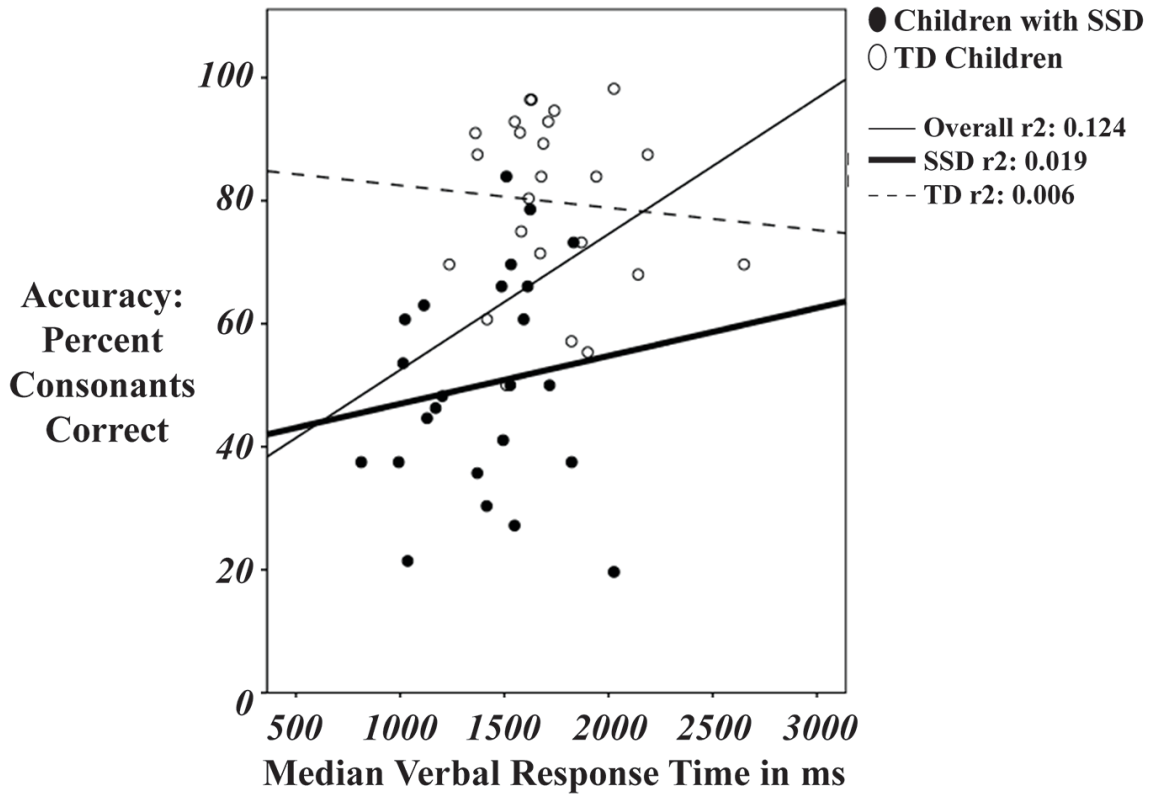

B. Consonant Place of Articulation x Overall Median Verbal Response Time

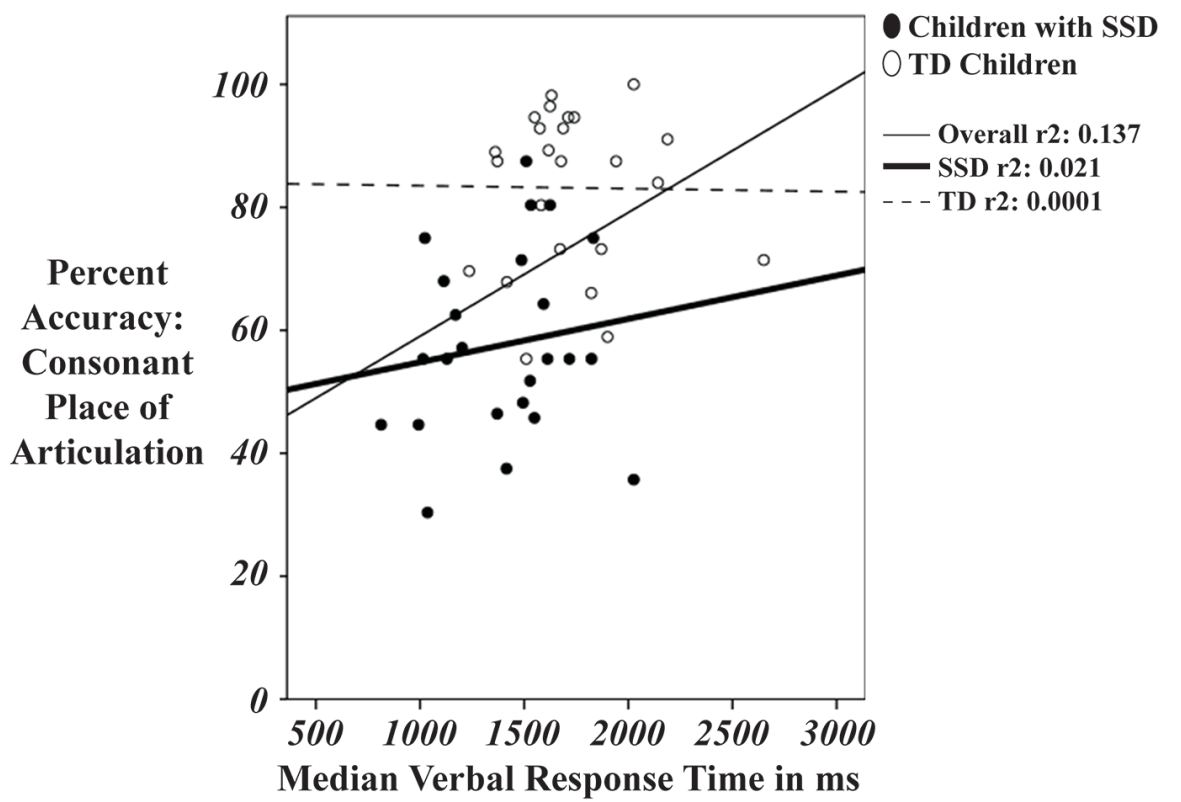

C. Consonant Manner of Articulation x Overall Median Verbal Response Time

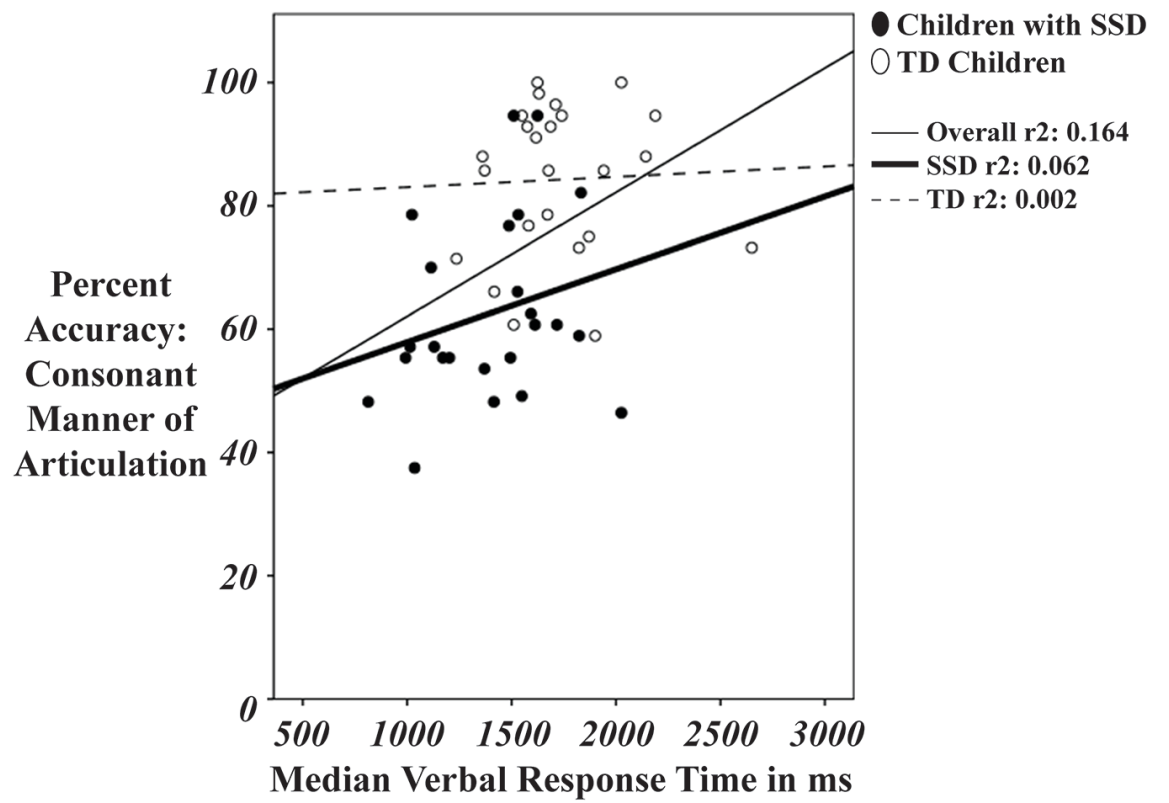


A. GFTA-2 Standard Score x Overall Median Verbal Response Time

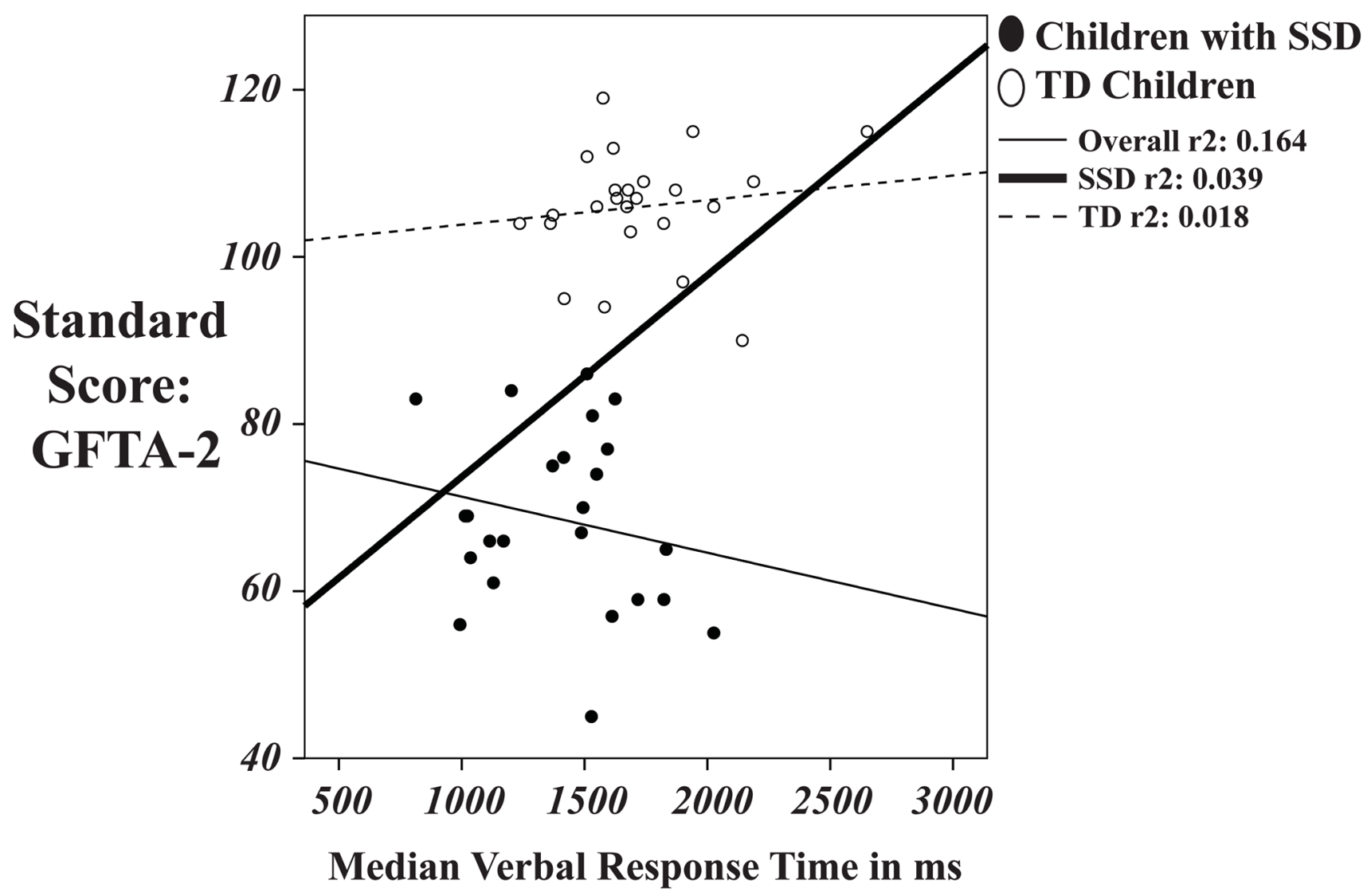

B. PPVT-2 Standard Score x Overall Median Verbal Response Time

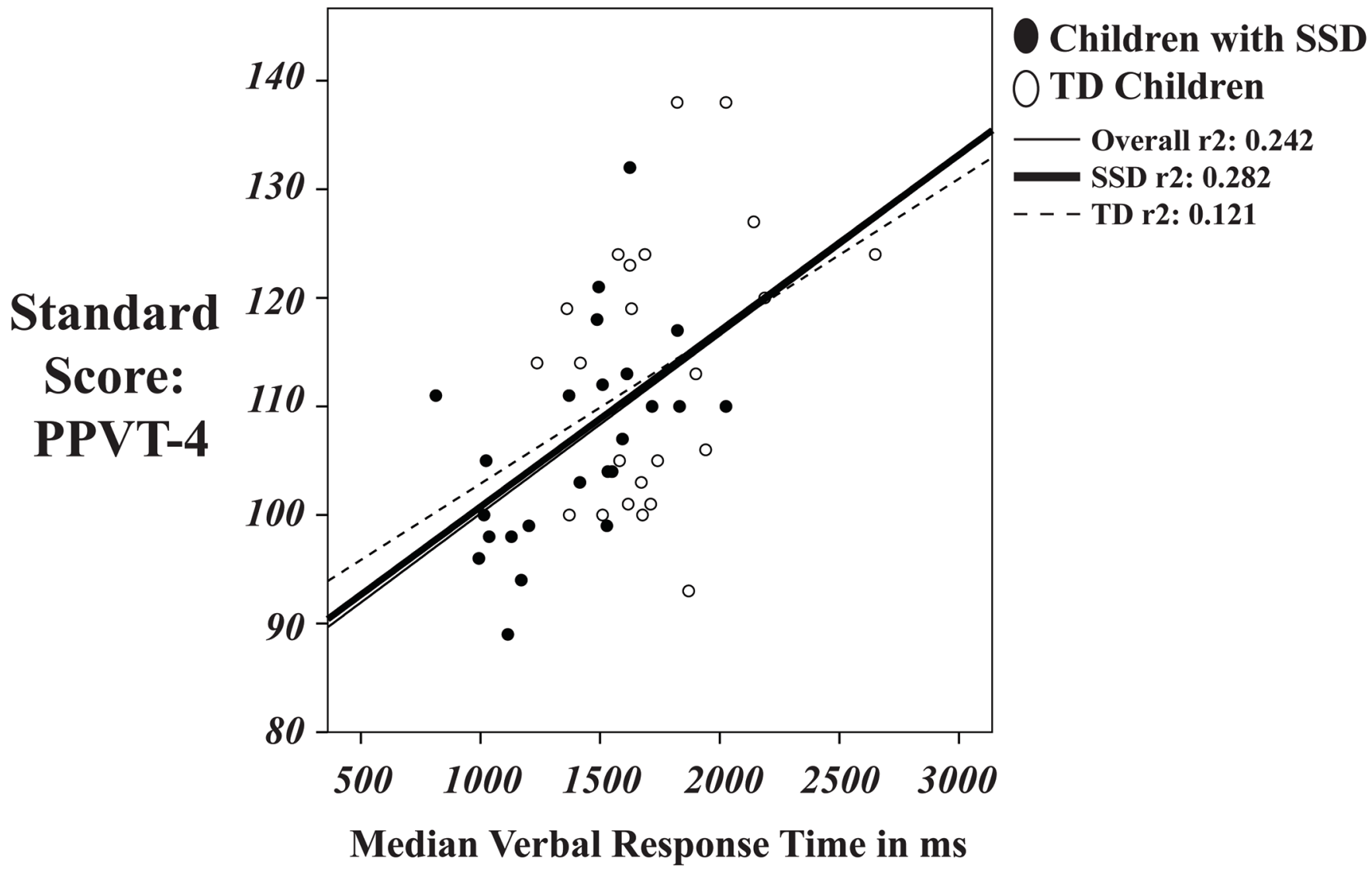

